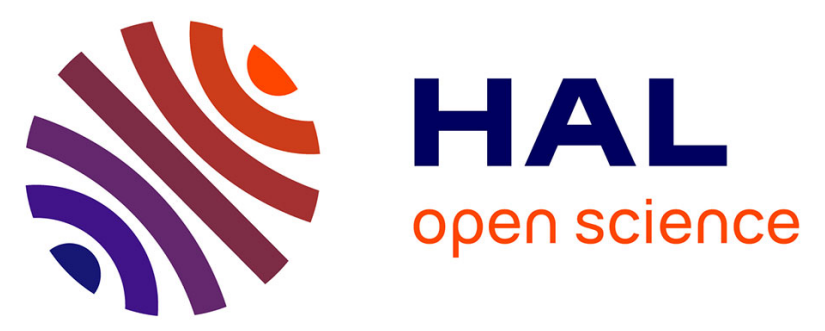

\title{
Introduction to the Maïdo Lidar Calibration Campaign dedicated to the validation of upper air meteorological parameters
}

\author{
Philippe Keckhut, Yann Courcoux, Jean-Luc Baray, Jacques Porteneuve, \\ Hélène Vérèmes, Alain Hauchecorne, Davide Dionisi, Françoise Posny, \\ Jean-Pierre Cammas, Guillaume Payen, et al.
}

\section{To cite this version:}

Philippe Keckhut, Yann Courcoux, Jean-Luc Baray, Jacques Porteneuve, Hélène Vérèmes, et al.. Introduction to the Maïdo Lidar Calibration Campaign dedicated to the validation of upper air meteorological parameters. Journal of applied remote sensing, 2015, 9 (1), pp.094099. 10.1117/1.JRS.9.094099 . insu-01145508

\section{HAL Id: insu-01145508 \\ https://hal-insu.archives-ouvertes.fr/insu-01145508}

Submitted on 21 Oct 2016

HAL is a multi-disciplinary open access archive for the deposit and dissemination of scientific research documents, whether they are published or not. The documents may come from teaching and research institutions in France or abroad, or from public or private research centers.
L'archive ouverte pluridisciplinaire HAL, est destinée au dépôt et à la diffusion de documents scientifiques de niveau recherche, publiés ou non, émanant des établissements d'enseignement et de recherche français ou étrangers, des laboratoires publics ou privés. 


\section{Applied Remote Sensing}

\section{Introduction to the Maïdo Lidar Calibration Campaign dedicated to the validation of upper air meteorological parameters}

Philippe Keckhut Yann Courcoux Jean-Luc Baray Jacques Porteneuve Hélène Vérèmes Alain Hauchecorne Davide Dionisi

Françoise Posny Jean-Pierre Cammas Guillaume Payen
Franck Gabarrot Stephanie Evan Sergey Khaykin Rolf Rüfenacht Brigitte Tschanz Niklaus Kämpfer Philippe Ricaud Abdel Abchiche Jimmy Leclair-de-Bellevue Valentin Duflot 


\title{
Introduction to the Maïdo Lidar Calibration Campaign dedicated to the validation of upper air meteorological parameters
}

\author{
Philippe Keckhut, ${ }^{\mathrm{a}, *}$ Yann Courcoux, ${ }^{\mathrm{a}, \mathrm{b}, \mathrm{c}}$ Jean-Luc Baray, ${ }^{\mathrm{d}, \mathrm{e}}$ \\ Jacques Porteneuve, ${ }^{\mathrm{a}}$ Hélène Vérèmes, ${ }^{\mathrm{d}}$ Alain Hauchecorne, ${ }^{\mathrm{a}}$ \\ Davide Dionisi, ${ }^{\text {a,f }}$ Françoise Posny, ${ }^{\mathrm{d}}$ Jean-Pierre Cammas, ${ }^{\text {, }}$
} Guillaume Payen, ${ }^{\mathrm{b}}$ Franck Gabarrot, ${ }^{\mathrm{b}}$ Stephanie Evan, ${ }^{\mathrm{d}}$ Sergey Khaykin, ${ }^{\mathrm{a}}$ Rolf Rüfenacht, ${ }^{\mathrm{g}}$ Brigitte Tschanz,, ${ }^{\mathrm{g}}$ Niklaus Kämpfer, ${ }^{\mathrm{g}}$ Philippe Ricaud, Abdel Abchiche, ${ }^{,}$Jimmy Leclair-de-Bellevue, ${ }^{d}$ and Valentin Duflot ${ }^{b}$

${ }^{a}$ CNRS, UVSQ UniverSud Paris, UPMC Paris-Sorbonne, UMR8190, Laboratoire Atmosphères, Milieux, Observations Spatiales-IPSL, Guyancourt 78289, France

${ }^{\mathrm{b}}$ CNRS, Université de la Réunion, UMS3365, Observatoire des Sciences de l'Univers de La

Réunion, Saint Denis de la Réunion 97744, France

'DGA, Maîtrise de l'information, Rennes 29240, France

${ }^{\mathrm{d}}$ CNRS, Université de la Réunion-Météo-France, UMR8105, Laboratoire de l'Atmosphère et des Cyclones, Saint Denis de la Réunion 97744, France

${ }^{e}$ CNRS, Université Blaise Pascal, UMR6016, CNRS-Observatoire de Physique du Globe de Clermont-Ferrand, Laboratoire de Météorologie Physique, Clermont-Ferrand 63171, France

${ }^{\mathrm{f}}$ Consiglio Nazionale delle Ricerche, Istituto di Scienze dell'Atmosfera e del Clima, Roma

00133, Italy

${ }^{g}$ University of Bern, Institute of Applied Physics, 3012 Bern, Switzerland

${ }^{\text {h}}$ CNRS, Meteo-France, UMR 3589, Centre National de Recherches Météorologiques, Toulouse,

France

${ }^{\mathrm{i}}$ CNRS, INSU, Division Technique, Meudon 91195, France

\begin{abstract}
The first operations at the new High-altitude Maïdo Observatory at La Réunion began in 2013. The Maïdo Lidar Calibration Campaign (MALICCA) was organized there in April 2013 and has focused on the validation of the thermodynamic parameters (temperature, water vapor, and wind) measured with many instruments including the new very large lidar for water vapor and temperature profiles. The aim of this publication consists of providing an overview of the different instruments deployed during this campaign and their status, some of the targeted scientific questions and associated instrumental issues. Some specific detailed studies for some individual techniques were addressed elsewhere. This study shows that temperature profiles were obtained from the ground to the mesopause $(80 \mathrm{~km})$ thanks to the lidar and regular meteorological balloon-borne sondes with an overlap range showing good agreement. Water vapor is also monitored from the ground to the mesopause by using the Raman lidar and microwave techniques. Both techniques need to be pushed to their limit to reduce the missing range in the lower stratosphere. Total columns obtained from global positioning system or spectrometers are valuable for checking the calibration and ensuring vertical continuity. The lidar can also provide the vertical cloud structure that is a valuable complementary piece of information when investigating the water vapor cycle. Finally, wind vertical profiles, which were obtained from sondes, are now also retrieved at Maïdo from the newly implemented microwave technique and the lidar. Stable calibrations as well as a small-scale dynamical structure are required to monitor the thermodynamic state of the middle atmosphere, ensure validation of satellite sensors, study the transport of water vapor in the vicinity of the tropical tropopause and study their link with cirrus clouds and cyclones and the impact of small-scale dynamics (gravity waves) and their link with the mean state of the mesosphere. (C) 2015 Society of Photo-Optical Instrumentation Engineers (SPIE) [DOI: 10.1117/1.JRS.9.094099]
\end{abstract}

Keywords: middle atmosphere; water vapor; temperature; wind.

Paper 14593 received Oct. 7, 2014; accepted for publication Mar. 19, 2015; published online Apr. 23, 2015.

*Address all correspondence to: Philippe Keckhut, E-mail: Keckhut@latmos.ipsl.fr

$1931-3195 / 2015 / \$ 25.00$ @ 2015 SPIE 


\section{Introduction}

During the last decades, much attention has been deployed by the scientific community for developing routine observations from the ground concerning the upper air atmospheric composition. Motivations were driven by the possibility to better understand the processes governing atmospheric variability and ensure detection of atmospheric responses associated with anthropogenic forcing. This concerns stratospheric ozone depletion, greenhouse gas increase, air quality issues, and aerosols. Dedicated scientific networks have been initiated for these respective issues from local to international frameworks. For example, the Network for the Detection of Stratospheric Changes, ${ }^{1}$ the Total Carbon Column Observing Network, ${ }^{2}$ the Integrated Carbon Observation System, ${ }^{3}$ the European Monitoring and Evaluation Program, ${ }^{4}$ and the European Aerosol Research Lidar Network. ${ }^{5}$ Surprisingly, fewer efforts have been devoted to setup a dedicated network for dynamical parameters and water vapor because these measurements were already performed worldwide for the meteorological forecasts mainly with the radiosonde network. The time evolutions from the radiosonde series suffer from discontinuities, ${ }^{6,7}$ requiring the selection of "less-disturbed" stations or the application corrections/adjustments 8,9 for accurate global trend estimates. ${ }^{10}$ However, an accurate network using radiosondes is strongly required for climate monitoring. ${ }^{11}$ Temperature satellite series are performed using a succession of experiments in space. However, time adjustments remain a major challenge for global trend estimates ${ }^{12}$ and require a reliable ground-based network. Water vapor is also a critical climate variable due to its greenhouse effect, its large spatial and temporal variability, and its role in chemistry and cloud formation.

The water vapor time evolution in the stratosphere is linked to methane oxidation and the transport processes. The water vapor density and in the upper-troposphere lower-stratosphere (UTLS) is of prime importance for radiative effects ${ }^{13,14}$ while the combined water vapor/ lapse rate feedback is to amplify the warming in response to forcing by around $50 \%$. Accurate measurements of water vapor in the UTLS are still difficult to perform from space due to the large vertical decrease and stratification. ${ }^{15}$ Upper tropospheric clouds, such as cirrus, have also been identified as one important regulator of the radiance balance of the Earth-atmosphere system. ${ }^{16}$ However, the net radiative effect depends on the competition between greenhouse and albedo effects that are linked to the microphysics, the height, the temperature, and the water vapor density.

While network for the detection of stratospheric changes (NDSC) was initially dedicated to stratospheric ozone, it also includes temperature and water vapor measurements from Lidar, microwave, and balloon techniques. To respond to the UTLS challenges, NDSC broadened its observation domain and was renamed Network for the Detection of Atmospheric Composition Change (NDACC). It was also decided to include the promising water vapor Raman lidar technique. At the same time, under the framework of the Global Climate Observing System (GCOS), a new international reference observing network designed specifically to meet climate requirements and called GCOS Reference Upper-Air Network (GRUAN) was proposed. This network focuses its first priority on the surface and on the reference upper-air meteorological variables (pressure, temperature, and water vapor), using radiosondes and water vapor total columns from the groundbased Global Navigation Satellite System (GNSS). The second priority extends to remote sensors including lidar, radar, and spectrometers and includes second priority parameters like wind profiles, surface radiation parameters, and total column or profile measurements of ozone, methane, and aerosols. Aerosols were measured worldwide by spectrometers like those deployed by AERONET $^{17}$ and lidar through the atmospheric radiation measurements site in the United States $^{18}$ and EARLINET in Europe, which are all included in the international GAW Aerosol Lidar Observation Network. There are some overlaps between those networks and several "super sites" using their complements for hosting several of these networks and providing a full spectrum of instruments. These research networks share the objectives of the data quality check based on a careful documentation of the instrument history and frequent validation campaigns.

Water vapor was the focus of some recent campaigns in the mid-western part of the United States, ${ }^{19}$ California, ${ }^{20}$ the Black Forest in Germany, ${ }^{21}$ Hawaii, ${ }^{22}$ and the Observatory of Haute-Provence in the south of France. ${ }^{23}$ In the southern hemisphere and more specifically 
over tropics, few long-term observation commitments are performed. Two decades ago, an atmospheric station was developed in the Indian Ocean at La Reunion Island $\left(21^{\circ} \mathrm{S}, 55^{\circ} \mathrm{E}\right)$ (more precisely, in 1994). ${ }^{24}$ Instruments were implemented in the University at Saint Denis on the northern coast of the Island. Instruments, developed and continuously operated, were dedicated mainly to the stratosphere. The development of the instrumental park has followed NDSC-NDACC guidelines and objectives. ${ }^{1}$ NDACC-labeled and candidate instruments include meteorological and ozone balloon sondes, the aerosol-temperature lidar, the water vapor additional lidar channels, the tropospheric and the stratospheric ozone lidars, the ozone and $\mathrm{NO}_{2}$ column measurements performed by UV-visible spectrometers $\mathrm{SAOZ}$, and the Fourier transform infrared solar absorption spectrometers for measuring columns of ozonerelated gases.

NDACC instruments were validated using continuous comparison campaigns with collocated operations, using mobile transfer instruments, data exchange and software comparisons, or satellite observations. Results for such intercomparisons were reported in dedicated publications for temperature lidars, ${ }^{25}$ microwave water vapor instruments ${ }^{26}$ and sondes. ${ }^{27}$

Since 2012, a new high-altitude facility has been built at the Maïdo mount, 2200-m above sea level. ${ }^{28}$ The objective was primarily to ensure a continuity of NDACC observations, previously conducted at the main town, Saint Denis, at sea level, with better atmospheric transparency conditions mainly for FTIR and microwave instruments. Such a dedicated observatory also allows hosting ancillary observations belonging to other companion networks dedicated to atmosphere investigations, to involve more in-situ measurements for background conditions while the site is theoretically less polluted by local emissions, ${ }^{29}$ and to offer better opportunities for hosting international collaborative instruments and campaigns that are required for the data quality insurance. In 2012, instruments operating previously at Saint Denis University moved to the new observatory which also contained many other new instruments. The lidar dedicated initially to temperature including tropospheric ozone, aerosols-clouds, and water vapor was fully redesigned and emerged as two new distinct instruments; one dedicated to water vapor and temperature with increased capabilities and one for aerosols and tropospheric ozone.

After a 6-month trial period dedicated to fixing different lidars and to conducting reliability tests, the first campaign organized within the Maïdo observatory was conducted in April 2013 for a 5-week intensive phase and in November 2013 for investigating instrument stability. This first campaign was preliminarily dedicated to upper air thermodynamic measurements (water vapor and temperature) while a dedicated international NDACC campaign is planned with ozone measurements as the main focus. The objectives of the campaign named MALICCA for Maïdo Lidar Calibration Campaign was the validation of the instruments measuring water vapor and dynamic parameters like temperature and wind and their cross-validation. The first scientific investigations on the UTLS transport and on atmospheric dynamics using data from these new instruments are illustrated. Some operational tests to insure that all instruments can run simultaneously without interferences or logistic drawbacks were conducted in order to prepare an intercomparison campaign in the NDACC framework. This publication intends to describe this campaign and to provide more detailed information about objectives and key scientific issues covered during this campaign. More detailed and specific results will be published elsewhere.

\section{Instruments for Thermodynamic Parameters}

\subsection{Temperature}

Temperature profiles from 30 to $80 \mathrm{~km}$ have been retrieved using Rayleigh lidar located at the University of La Reunion, in the northern part of the island from 1993 to 2011. The method is based on the vertical emission of a laser pulse. The backscattered signal is collected with large telescopes. The temperature is deduced from molecular scattering assuming the ideal gas law ${ }^{30}$ and uncertainties were quantified. ${ }^{31}$ Temperature profiles were extended downward using the Nitrogen Raman channel. ${ }^{28}$ This lidar system has operated in the framework of the NDACC 


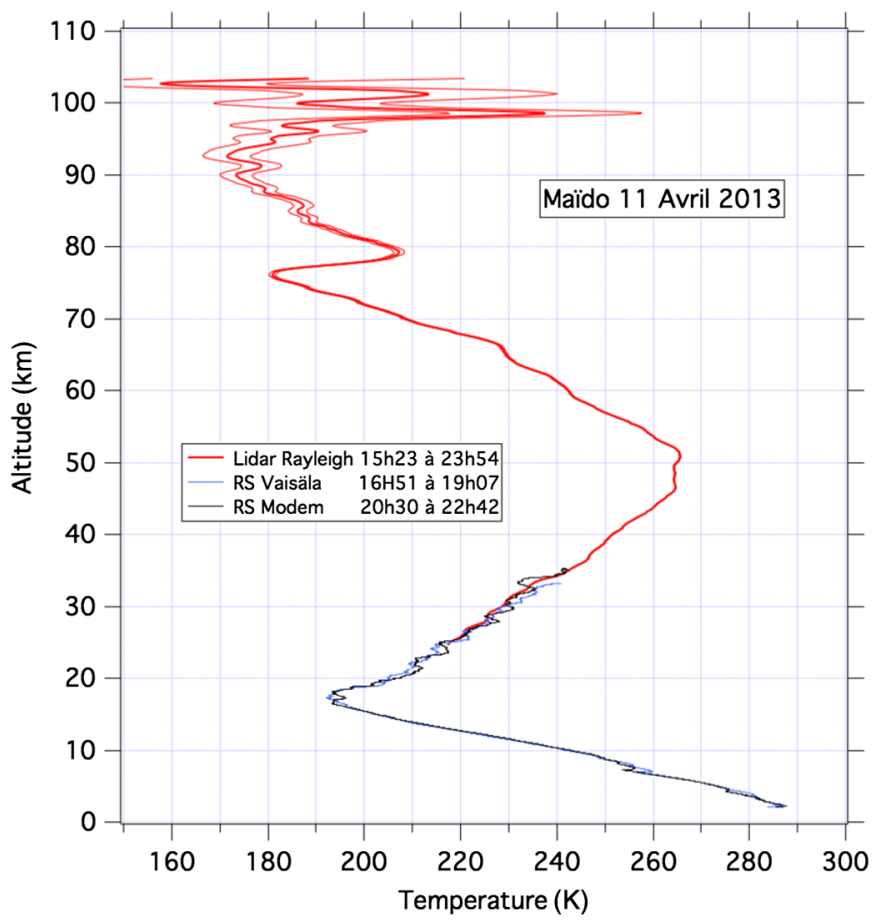

Fig. 1 The Lidar temperature profile obtained on April 11, 2013, compared with simultaneous M10 Modem and RS92 Vaisala radiosondes. Thin lines correspond to statistical and systematic (detector linearity, background noise and initialization, adjustment of low and high channels) uncertainties $( \pm 1 \sigma)$.

and the successive configurations of the Rayleigh-Raman lidar setup are available in Refs. 24 and 25. Measurements were used for dynamic investigations including gravity waves and atmospheric tides and were allowed to provide temperature for satellite validation and long-term monitoring in the tropics ${ }^{32}$ where no similar measurements were available in the Southern Hemisphere. Temperature changes during this last decade do not show the expected cooling, therefore, future measurements are essential. The challenge will consist of ensuring the long-term continuity between both instruments and locations from sea level at the University to the Maïdo $(2200 \mathrm{~m})$. The impact of the instrumental upgrade mainly induced by the additional capability of the water vapor measurements simultaneously with the continuation of the temperature series is the main challenge. Numerous temperature profiles were obtained during the MALICCA. In the overlap domain ( 25 to $35 \mathrm{~km}$ ), comparisons show a good agreement (smaller than $1 \mathrm{~K}$ ) with simultaneous radiosondes (Fig. 1) and demonstrate improved lidar capabilities providing profiles up to $100 \mathrm{~km}$. Future validation will also be ensured with the collocated NASA mobile lidar. ${ }^{33}$ The proposed strategy to ensure longterm continuity will consist of using radiosondes and Rayleigh profiles also derived from the ozone lidar (in the domain 25 to $70 \mathrm{~km}$ ) with a specific design, in contrary to the Rayleigh temperature lidar that has not changed during the move from one site to the other.

The lidar capabilities have been improved compared to the previous one in operation in the university at ground level by a factor of more than 6 regarding laser power and collector surface and provide an increase of the range domain of more than $20 \mathrm{~km}$. As an example (Fig. 1), after $8 \mathrm{~h}$ of integration, an accuracy better than $\pm 1 \%$ up to 75 to $80 \mathrm{~km}$ is achieved for a vertical resolution of $1 \mathrm{~km}$. This improvement also benefits from the station altitude and the good transparency as well as an improved design. ${ }^{25}$

Radiosondes launched from meteorological balloons are performed weekly within the NDACC with ozone sondes since $1992^{24}$ and under the national meteorological organization, both using now the M10 Modem sondes. Daily meteorological soundings were performed at Tromelin Island (535 km north of La Réunion) and have been transferred by Météo-France to La Réunion Island since June 2011 for operational reasons and for the greater benefit of the scientific synergy with the High altitude Observatory at Maïdo. ${ }^{28}$ Several types of meteorological 
sondes have been used (Vaïsala RS92, Modem M2K2 and M10). The time continuity has been ensured by performing, at each main sonde changes, intercomparison campaigns using several dual launches with gondolas equipped with both types of sondes. During the MALICCA, the new M10 modem sondes were tested and time continuity was investigated. Comparisons with other types of sondes are important to better characterize their accuracy and their usefulness for climate issues. Such an approach is required to enter the GRUAN. ${ }^{34}$ During the MALICCA, progress has been applied to the calibration methodology using the ground check and also concerning some missing corrections that now provide water profiles in good agreement with Vaisala sondes and the lidar.

\subsection{Water Vapor and Cirrus Clouds}

A new lidar instrument for measuring water vapor was designed and built at the Maïdo observatory thanks to the experience acquired with the Raman channels added on the existing Rayleigh $\operatorname{lidar}^{35}$ at the University at Saint-Denis. The system includes several innovative parts and upgrades to ensure an accurate monitoring of the UTLS. The increase of the laser power, the surface collector, the station altitude, the detector efficiency, and the modification of the emitted wavelength from 532 to $355 \mathrm{~nm}$ have improved the lidar signal by a factor of around 150 and the altitude range up to the tropopause height. The laser emission and the telescope receiver were arranged with a coaxial structure allowing measurements starting from the ground to the tropopause, ensuring a calibration independent of radiosounding and based on integrated water vapor (IWV) collocated ancillary measurements. This calibration was one of the objectives of this campaign. Such lidar can also provide vertical profiles of the scattering ratio that document aerosols' optical parameters and the vertical cloud location and shape. With this lidar configuration, the elastic channel is saturated by the large backscattering and particles can only be detected above $8 \mathrm{~km}$.

Another lidar, the Leosphere ALS450, previously used for shipborn campaigns in the Indian Ocean, ${ }^{36}$ is used to measure aerosols and clouds under $8 \mathrm{~km}$. It is based on a Nd:Yag laser producing pulses with a mean energy of $16 \mathrm{~mJ}$ at $355 \mathrm{~nm}$ and a frequency of $20 \mathrm{~Hz}$. Lidar measurements have been averaged over 2 min with a vertical resolution of $15 \mathrm{~m}$. Lidar profiles enable the retrieval of aerosol optical properties and atmospheric structures such as cirrus clouds.

Water vapor measurements have been measured with a lidar located at sea level (Saint Denis) from 2001 to 2005, and since 1993, with radiosondes for both temperature and ozone. However, water vapor was not the main interest as balloons were dedicated to the ozone sounding, and the Vaisala RS80 sensors used in the 90s had a large uncertainty for humidity over $10 \mathrm{~km} .{ }^{37}$ Such a campaign leads to numerous improvements of water vapor radiosonde measurements and due to the transport issues, similar to temperature, a long series will be constructed and the sensors' continuity will be ensured by regular campaigns.

Ground-based global positioning system (GPS) receivers allow retrieving IWV estimates ${ }^{38}$ from several simultaneous satellite emissions. GPS receivers are operating continuously and in all weather conditions. Measurement accuracy depends on the available satellites at the time of measurements and on atmospheric conditions. Estimates of the measurement accuracy uses a GPS range between 0.5 and $2.5 \mathrm{~kg} \mathrm{~m}^{-2},{ }^{39}$ while collocated reference measurements are missing and exhibit different views. While GPS IWV measurements are affected by interferences of the direct signal transmitted by a satellite and the signals scattered and reflected from the environment around the ground-based antenna, it is crucial to evaluate such measurements while the Maïdo station is located on an island with a complex orography. A Trimble NetR9 GNSS reference receiver coupled to a Zephyr Geodetic 2 Antenna has been set up at the Maïdo station since March 2013 and is used for lidar calibration. Many other GPS receivers are deployed on the island and can be used to produce vertical profiles of water vapor using the tomography technique. ${ }^{40}$

In the framework of biomass burning investigations of the transport of aerosols over the Indian Ocean, a set of two Microtops II sun-photometers has been operated under Reunion Island Observatory responsibility since $2008 .^{36}$ When not used for campaigns onboard scientific ships cruising in the Indian Ocean to collect data, ${ }^{41,42}$ these two instruments have been used at the 
Maïdo facility from September 2012 to the end of April 2013. Periodically, the instruments are sent back to the Maritime Aeronet Network (MAN) headquarter at NASA GSCF for calibration. ${ }^{43}$ Microtops II serial number 14975 was operated during the 5 weeks of MALICCA in April 2013, enabling Aerosol Optical Transmission at 379, 441, 674, and $868 \mathrm{~nm}$ and water vapor measurements.

Water vapor profiles in the upper stratosphere and the mesosphere can also be detected by ground-based microwave radiometry. For details about monitoring atmospheric water vapor, we refer to a monograph ${ }^{44}$ and to a chapter dedicated to microwave radiometry. ${ }^{45}$ Water vapor profiles can be retrieved from spectral measurements of pressure broadened emission lines in the microwave part of the spectrum. Ground-based observations are performed at a frequency of $22.235 \mathrm{GHz}$. Observation sites at high altitude are preferable as a low tropospheric opacity guarantees a higher signal-to-noise ratio of the spectral feature of the middle atmosphere. Measurements of the opacity at $22 \mathrm{GHz}$ over 8 months on Maïdo observatory with the MIAWARA-C instrument of the Institute of Applied Physics, University of Bern, revealed values below 0.068 for $50 \%$ of the time, with very low values ( 20\% less than 0.02$)$ during the night which proves the excellent observation conditions at the Maïdo facility.

Two microwave radiometers for water vapor were in operation during the campaign, one from France and one from Switzerland. In April, during the first part of the campaign, the ground-based microwave radiometer DODO, funded by Université de la Réunion (France) and developed at Laboratoire d'Aérologie, Toulouse (France), and Technical Division of INSU, Meudon (France) provided few data. This radiometer is based on a previous instrument and was already described in detail. ${ }^{46,47}$ DODO measured a few spectra of water vapor in April. Unfortunately, these spectra are not calibrated and, therefore, do not allow the retrieval of an altitude profile.

In September 2013, the ground-based microwave radiometer for middle atmospheric water vapor MIAWARA-C from the University of Bern was installed at the Maïdo observatory. Since then, the instrument has continuously operated with the exception of the cyclone period Bejisa in January 2014 and some minor measurement gaps due to technical problems. The measurements allow the retrieval of middle atmospheric water vapor profiles in the altitude range from 35 to $75 \mathrm{~km}$ under all nonprecipitating conditions. The profile is retrieved by performing an optimal estimation inversion technique on the measured emission line of water vapor centered at $22.235 \mathrm{GHz}$. Under most tropospheric conditions, water vapor profiles with a temporal resolution of $\sim 2$ to $6 \mathrm{~h}$ can be obtained. The vertical resolution is $\sim 15 \mathrm{~km}$. The instrument has a compact design and is operated remotely from its home institution. A detailed description of the instrument and its calibration scheme is provided in Straub et al. ${ }^{48}$ and a thorough description of the standard retrieval version of MIAWARA-C and validation against similar instruments and satellite experiments is presented in Tschanz et al. ${ }^{49}$

\subsection{Wind Measurements}

Wind measurements are critical in the tropical area, whereas thermal winds can differ from the real wind. Except for commercial meteorological balloons that provide, with GPS onboard, a wind measurement from the ground to $30 \mathrm{~km}$, very few techniques can provide such measurements in the 30 to $60 \mathrm{~km}$ domain. The future ADM-AEOLUS space mission will provide wind profiles and will require well-equipped stations like the Maïdo observatory for regular calibration.

Wind profiles can be derived using the Double Edge Doppler lidar technique. The second harmonic of a monomode $\mathrm{Nd}$ :Yag laser is alternately sent in the west and south directions at 45 deg elevation from the zenith using a rotating mirror. The two components of the horizontal wind are obtained from the measurement of the Doppler shift of the return signal spectrally filtered by a double-edge Fabry-Pérot etalon. A demonstration of the method that is similar to the ADM-AEOLUS mission was performed in 1989 at the Observatory of Haute-Provence, ${ }^{50}$ allowing climatology $y^{51}$ and gravity-wave investigations. ${ }^{52} \mathrm{~A}$ new system, using the same method but with a more compact design, was installed at the Maïdo observatory. Such a system will provide wind measurements from 10 to $50 \mathrm{~km}$ and measurements with an accuracy better 
than $1 \mathrm{~ms}^{-1}$ up to $30 \mathrm{~km}$. Measurements will be compared with both the radiosonde positioning system using GPS and the new microwave spectrometer.

The microwave Doppler spectroradiometer WIRA ${ }^{53}$ is a passive ground-based instrument specifically designed for the measurement of horizontal wind profiles in the altitude range of 35 to $70 \mathrm{~km}$. New developments in spectrometer and high frequency amplifier technologies enable microwave spectroradiometers to directly measure the Doppler shift induced by the movement of the emitters with the mean flow. In the case of WIRA, the analyzed microwave radiation originates from the ozone molecules emitting at $142 \mathrm{GHz}$. By coupling beams from the zonal and meridional directions into WIRA's optical path, a total picture of the horizontal wind field can be obtained. The altitude information is contained in the line shape of the measured spectrum. Wind profiles are calculated from the radiation measurement by applying an optimal estimation inversion technique to an atmospheric radiative transfer model. The altitude resolution for wind profiles measured by WIRA is $\sim 10 \mathrm{~km}$ in the stratosphere and 10 to $16 \mathrm{~km}$ in the mesosphere, while observation errors for daily average profiles lie between 10 and $20 \mathrm{~ms}^{-1}$ depending on the observation conditions. More details on the performances of the instrument and the retrieval including the averaging kernels and an in-depth error analysis are given in Rüfenacht et al. ${ }^{53}$ The microwave approach has the advantage of being operational independent of daylight conditions and only weakly being affected by cloud cover. Moreover, its operation is highly automated so that WIRA routinely measures a continuous wind profile time series.

\section{Campaign Operations}

The campaign was conducted with two phases. MALICCA-1 (April 2013) consisted of three main parts: 1 week dedicated to logistics (preparation and technical optimization of the operational instruments, installation of additional radiosonding capabilities), a 3-week intensive measurement phase, and a last less-intensive period with fewer instruments involved running on a routine mode.

During the first week, tests were conducted to evaluate whether or not the instruments can be operated at the same time without interferences between selected instruments.

The guidelines for the intensive phase were the following:

First, get high-quality data with the water vapor and temperature lidar in its two-operational configurations, either with one or two lasers emitting at $355 \mathrm{~nm}$. These data were acquired in parallel with measurements with all instruments that were previously identified as potential help for water vapor lidar calibration (GPS, Vaïsala RS-92 and Modem M10 radiosondes, sun-photometer, microwave radiometer). Depending on the weather conditions, continuous night-time lidar measurements from 2 to $8 \mathrm{~h}$ were conducted.

During lidar measurements, every $2 \mathrm{~h}$ a radiosonde was launched, either with one radiosonde (Modem M10 or RS92) or two radiosondes on the same gondola (M10 and RS92GP). RS92 sondes, including all the required corrections, were analyzed by the GRUAN team. ${ }^{54}$

GPS measurements were continuously conducted at the Maïdo facility. The tropospheric aerosol lidar was in operation day and night nearly all the time. It was mainly used for cirrus detection, complementary to water vapor measurements.

During the daytime, for the 5 weeks and as soon as the sky was clear, optical depth and water vapor measurements were also conducted at the Maïdo observatory. Data were sent to the MAN team at NASA GSFC for validation. Modem radiosondes were operated during this campaign since it is used in all French NDACC stations. A mobile station was operated at Maïdo in April and November 2013. The Vaisala RS 92 mobile system from CNRS/INSU and Meteo France was operated at Maïdo in April 2013 to enable comparisons with other similar campaigns, mainly those conducted by NASA teams for water vapor measurements. ${ }^{20,23}$ The tropospheric ozone lidar or Doppler wind lidar were in operation in parallel to the water vapor and temperature lidar.

MALICCA-2 (November 2013) aimed mainly at confirming some results acquired in April 2013, but under different meteorological conditions (dryer without any tropical storm in the vicinity of Reunion Island) and lasted 1 week. A wind and water vapor MIAWARA-C 
Keckhut et al.: Introduction to the Maïdo Lidar Calibration Campaign dedicated to the validation...

Table 1 List of specific measurements performed during the Maïdo Lidar Calibration Campaign.

\begin{tabular}{|c|c|c|c|c|c|c|}
\hline Date & $\mathrm{H}_{2} \mathrm{O}-\mathrm{T}$ Lidar & $\begin{array}{l}\text { Aerosol/cirrus } \\
\text { Lidar }\end{array}$ & $\begin{array}{l}\text { Sonde } \\
\text { Modem } \\
\text { M10 }\end{array}$ & $\begin{array}{c}\text { Sonde } \\
\text { Vaisala } \\
\text { RS92 }\end{array}$ & $\begin{array}{c}\text { MIAWARA-C } \\
\mathrm{H}_{2} \mathrm{O} \\
\text { radiometer }\end{array}$ & $\begin{array}{l}\text { WIRA wind } \\
\text { radiometer }\end{array}$ \\
\hline April 1 & $17: 51$ to $21: 42$ & $16: 58$ to $17: 40$ & & & & \\
\hline April 2 & $15: 19$ to $00: 39$ & $14: 20$ to $23: 03$ & $\begin{array}{l}16: 00 \\
21: 57\end{array}$ & & & \\
\hline April 3 & $17: 58$ to $20: 09$ & $17: 23$ to $23: 20$ & $\begin{array}{l}15: 17 \\
19: 44\end{array}$ & & & \\
\hline April 4 & $16: 35$ to $00: 31$ & $14: 35$ to $23: 59$ & $\begin{array}{l}15: 16 \\
19: 56 \\
\\
22: 12\end{array}$ & & & \\
\hline April 6 & - & $03: 41$ to $11: 07$ & & & & \\
\hline April 7 & $20: 46$ to $22: 03$ & $03: 26$ to $04: 48$ & $21: 59$ & & & \\
\hline April 8 & $15: 34$ to $21: 06$ & $04: 01$ to $18: 10$ & $19: 18$ & $\begin{array}{l}16: 08 \\
20: 50\end{array}$ & & \\
\hline April 9 & $15: 19$ to $23: 50$ & - & $\begin{array}{l}15: 38 \\
20: 19\end{array}$ & $\begin{array}{l}16: 03 \\
20: 41\end{array}$ & & \\
\hline April 10 & $15: 39$ to $21: 50$ & $06: 09$ to $16: 04$ & & $\begin{array}{l}14: 24 \\
20: 06 \\
\\
22: 37\end{array}$ & & \\
\hline April 11 & $15: 49$ to $23: 50$ & $06: 09$ to $22: 47$ & $16: 38$ & $\begin{array}{l}16: 50 \\
20: 30 \\
23: 50\end{array}$ & & \\
\hline April 13 & $16: 37$ to $18: 58$ & $16: 38$ to $18: 48$ & & $17: 05$ & & \\
\hline April 15 & $19: 46$ to $22: 34$ & & & $\begin{array}{l}16: 08 \\
19: 03\end{array}$ & & \\
\hline April 16 & $20: 35$ to $22: 09$ & $18: 22$ to $22: 50$ & & & & \\
\hline April 17 & $17: 32$ to $20: 56$ & $19: 00$ to $20: 40$ & & & & \\
\hline April 18 & $18: 49$ to $23: 59$ & & & & & \\
\hline April 20 & $14: 54$ to $22: 00$ & & & & & \\
\hline April 21 & $15: 13$ to $00: 03$ & & & & & \\
\hline April 22 & $14: 54$ to $20: 27$ & & & & & \\
\hline November 17 & $19: 59$ to $21: 04$ & & & & $24 \mathrm{~h}$ & $24 \mathrm{~h}$ \\
\hline November 18 & $17: 11$ to $18: 20$ & & & & $24 \mathrm{~h}$ & $24 \mathrm{~h}$ \\
\hline November 19 & $15: 34$ to $21: 26$ & & & & $24 \mathrm{~h}$ & $24 \mathrm{~h}$ \\
\hline November 20 & $15: 29$ to $20: 31$ & & & & $24 \mathrm{~h}$ & $24 \mathrm{~h}$ \\
\hline
\end{tabular}

microwave radiometer was also in operation during this second phase of the campaign (Table 1). ${ }^{48}$ Microwave radiometers have experienced sometime spurious emissions that decrease the quality of the retrievals. During this second phase, instruments run on a routine mode basis.

During both campaigns, we tried to adapt our strategy in order to synchronize the groundbased measurements with overpasses near Reunion Island of various satellites (AQUA, AURA, Megha-Tropique, TIMED-SABER). 


\section{Instrument Capabilities and Cross-Validation Issues}

\subsection{Water Vapor}

\subsubsection{Lidar calibration}

For an efficient monitoring, the calibration coefficient needs to be estimated with an accuracy better than a few percent. Collocated calibrations will be performed with a GPS IWV that is systematically available and has shown to present an adequate accuracy despite the local effect of orography that needs to be investigated. ${ }^{55}$ In addition, internal calibrations are ensured using a flash lamp and the sky background method ${ }^{34}$ to detect any sudden instrumental changes. Validation has been performed with RS-92 sondes that have already been well characterized and used for validation. This lidar measures over a large vertical range and the time integration over the whole campaign shows that accurate measurements can be obtained up to the lower stratosphere allowing the monitoring this altitude region with such approach.

The overall vertical distribution of water vapor is in good agreement between lidar and both radiosonde types (after applied required corrections) up to $20 \mathrm{~km}$ (Fig. 2). While lidar uncertainties mainly due to statistical noise increase with altitude, such an agreement gives better confidence of water vapor estimates at a lower altitude where instruments sometimes record different local structures and gradients as illustrated above $14 \mathrm{~km}$ in the example given in Fig. 2. However, further investigations are required to better understand whether the measurements are real or are due to spatiotemporal differences. Geophysical investigations with back trajectory approaches are complementary to validate the short-scale structures (seen Sec. 5).

\subsubsection{Meteorological Sonde Intercomparison}

The water vapor profiling allows evaluating the accuracy of water vapor measurements using sondes. The new Modem sondes were evaluated for the first time during the DEMEVAP campaign $^{23}$ in the south of France and revealed some disagreements. The investigations performed during the MALICCA indicate that the ground check in the calibration box with a reference sensor is not valid for calibration because of the long time required to reach temperature equilibrium while the firm calibration gives better results. With a good ground calibration, comparison with Vaisala sondes and the lidar is much better and small-scale structures are similar to the other instruments. Some other disagreements have been noticed. They are due to both radiative effects and the response time not being taken into account in the initial processing. After both effects were corrected, the agreement is better and the accuracy is close to that of the Vaisala RS92 sondes (Fig. 2). A detailed study of the sondes' accuracy during MALICCA has been performed during this campaign and will be the subject of a specific study. Other

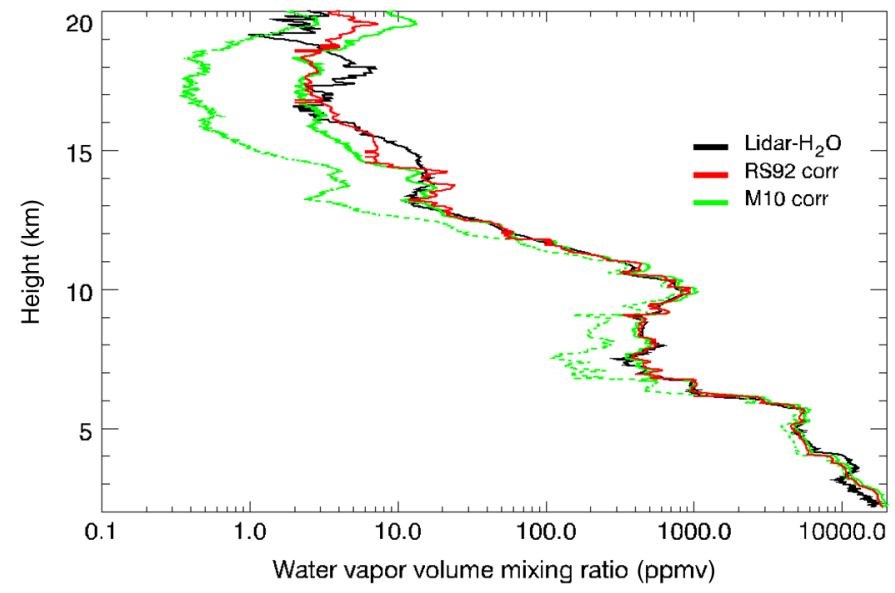

Fig. 2 Water vapor profiles on April 8, 2013, provided by lidar (black line), by a RS92 sonde (red line) corrected following the GCOS Reference Upper-Air Network protocol, ${ }^{54}$ and a Modem sonde (green lines) with and without similar corrections (radiative and response time). 
campaigns involving Modem sondes in the frame of GRUAN and WMO are planned in the next years.

\subsubsection{Water vapor microwave radiometer}

The time series of water vapor profiles obtained at Maïdo during the campaign in November by the microwave instrument MIAWARA-C is shown in Fig. 3. During the second phase of MALICCA, MIAWARA-C has been measuring without interruption and under good tropospheric conditions with a median $22 \mathrm{GHz}$ opacity of 0.055 . The resulting water vapor profiles with a time integration of $2 \mathrm{~h}$ are presented in Fig. 3. The reliable altitude range of this retrieval version is defined as the region where the area of the averaging kernel is larger than 0.8 and is indicated in the figure. Outside of the white line, the measurement response is less than $80 \%$ and the contribution to the retrieved profile by the a-priori information increases. For details on the reliable altitude range and vertical resolution, we refer to Straub et al. ${ }^{48}$ and Tschanz et al. ${ }^{49}$

\subsubsection{Validation of satellites water vapor measurements}

Satellites' water vapor measurements need to be evaluated mainly in the UTLS where large gradients and variabilities are difficult to trap with actual instrumentation. ${ }^{15}$ Such satelliteborne remote instruments as Microwave Limb Sounder (MLS)/Aura, Atmospheric Infrared Sounder (AIRS)/Aqua, COSMIC/FORMOSAT-3 or SAPHIR/Megha-Tropiques, retrieve profiles of water vapor in the troposphere and in the stratosphere. The accuracy would depend on the performance of the instrument that is relative to the altitude. For example, AIRS has a limited sensitivity in the lower stratosphere for mixing ratios below 10 ppmv. ${ }^{56}$ Intercomparisons of $\mathrm{H}_{2} \mathrm{O}$ measurements with respect to ground and space-borne instruments in the tropics and subtropics have been investigated, as was done for the HIBISCUS campaign, ${ }^{15}$ in order to evaluate the quality of satellites' data in the specific context of such areas. When comparing balloon flights and AIRS measurements, an agreement of $25 \%$ in the tropics in the upper stratosphere has been identified. ${ }^{57}$ Many campaigns have involved radiosoundings to validate satellites. Using Raman lidar measurements is not that usual and provides external measurements as all sondes face similar limitations. The campaign AIRS Water Vapor Experiment-Ground (AWEX-G, October to November 2003) was aimed at bringing the most accurate instruments involved in AIRS validation to monitor water vapor in a same site for intercomparison. ${ }^{58}$ However, corrections need to be applied to the scanning Raman lidar for Aqua

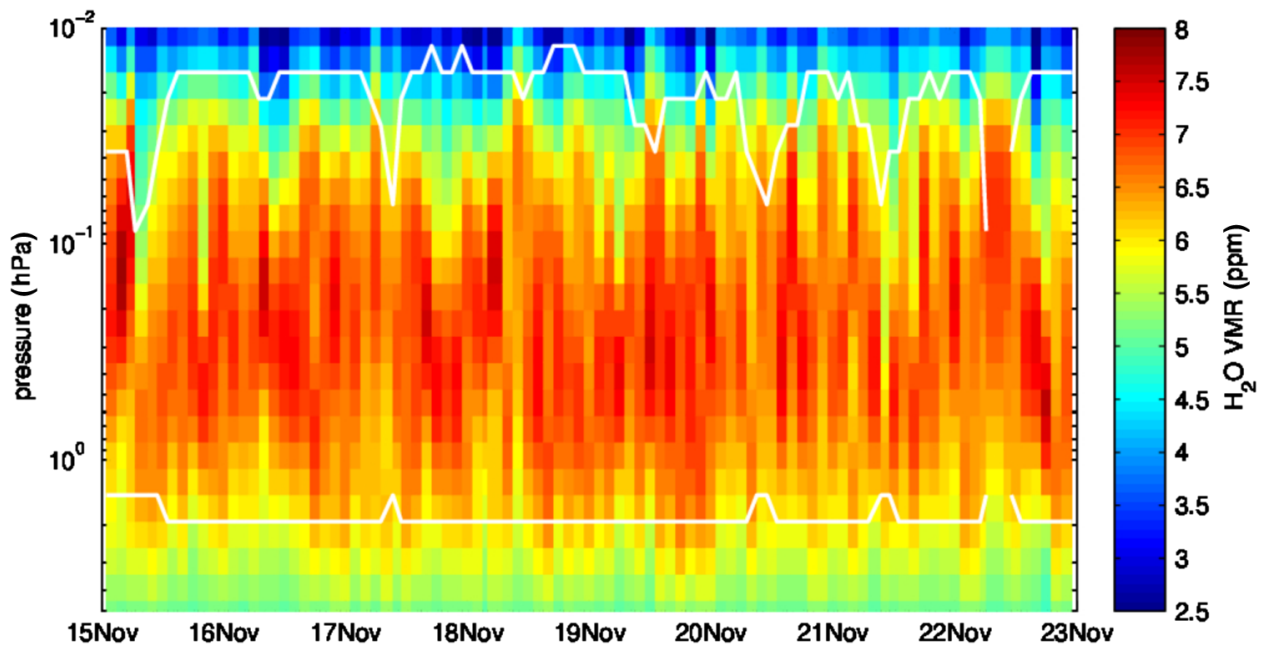

Fig. 3 Water vapor measured by MIAWARA-C at Maïdo observatory during the second phase of Maïdo Lidar Calibration Campaign with an integration time of $2 \mathrm{~h}$. The white horizontal lines indicate the upper and lower limits of the sensitive altitude range (defined as the area of the averaging kernel $>0.8$ ). 


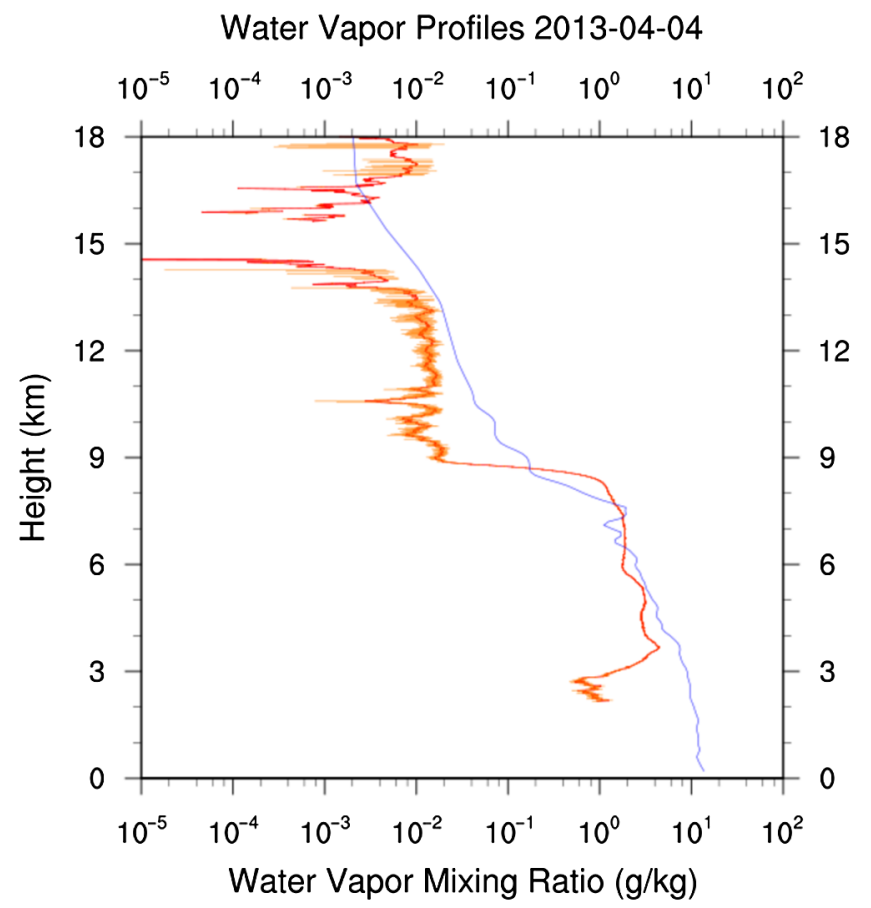

Fig. 4 Water vapor mixing ratio measurements on April 4, 2013, obtained with the Raman lidar at the Maïdo observatory between 23:03 and 0:29 UTC compared with the COSMIC retrieval at 23:34 UTC (16.11S, 57.38E) corresponding to an air mass located $650 \mathrm{~km}$ apart on the North.

validation efforts. The validation of the NASA/Aura/MLS water vapor at Mauna Loa by a Raman lidar focused on the troposphere ${ }^{59}$ because, even if the MLS profiles are better in the stratosphere, the sensitivity of the lidar is not good enough at that height. Even if all the studies showed that lidars were accurate enough for satellite validation, they were mainly restricted to the troposphere. The Maïdo observatory lidar would be efficient for validations in the (sub-)tropical UT/LS. A few intercomparisons between satellites and Raman lidars are quite recent, such as the work on COSMIC-RO data and the lidar of the CIAO (CNRIMAA Atmospheric Observatory) in Potenza, South Italy. This lidar operation at Maïdo would represent an asset in the validation of satellites considering its performances. An example of COSMIC and Maïdo Raman lidar measurements (Fig. 4), even when far apart (650 km), illustrates the new Raman lidar's ability to perform satellites' validation such as GPS-RO soundings that should be provided by the future tropical constellation of the COSMIC-2 mission. This lidar proved its ability to provide water vapor vertical profiles with a better vertical resolution in the upper troposphere (12 to $18 \mathrm{~km}$ ) than GPS measurements. Density differences around 9 and $15 \mathrm{~km}$ can be partly due to the resolution and also due to geolocation reasons when measurements are separated by up to several hundred kilometers. Statistical comparisons will be required to quantify any significant potential instrumental differences, whereas GPS can provide a quasiglobal measurement.

\subsection{Temperature}

Rayleigh lidars provide absolute temperature measurements. Radiosondes temperature measurements allow a direct comparison around 25 to $35 \mathrm{~km}$. This region is the most critical one for $\operatorname{lidar}^{27}$ as thin aerosol layers from minor volcanic eruptions may pass over the laser beam and bias temperature retrievals. The lidar signal in this altitude range is often large and may also induce bias due to photocounting saturation. The use of small fields of view can also induce uncertainty in this domain due to the defocalization effect. ${ }^{28}$ However, parallax effects are removed compared to the previous systems ${ }^{60}$ due to the coaxial geometry used in this case. Figure 1 shows an example of such comparisons with Modem and RS92 sondes. The lidar profile 

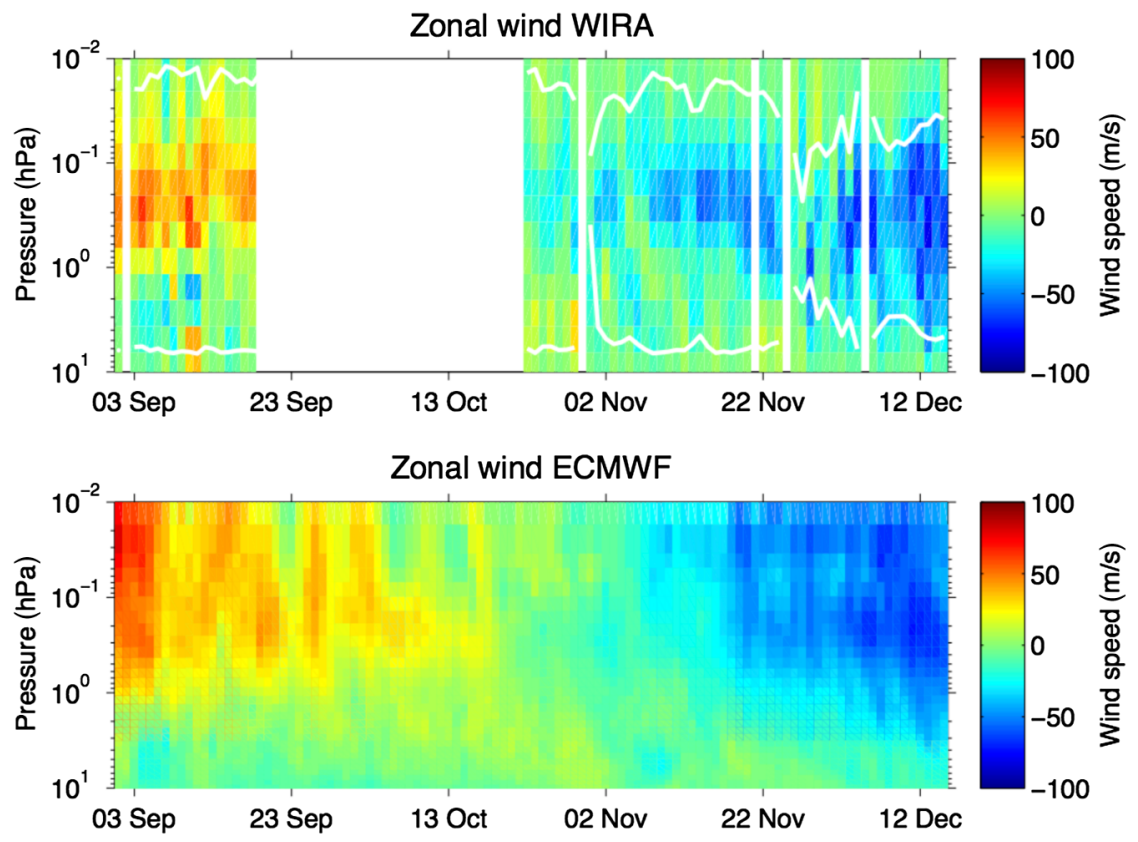

Fig. 5 Daily average zonal wind profiles observed by the wind radiometer WIRA at the Maïdo observatory (top panel) compared to operational ECMWF data analyses (bottom panel).

is retrieved with a $3-\mathrm{km}$ vertical smoothing showing an altitude range better that $100 \mathrm{~km}$ with an error increasing with altitude up to $10 \mathrm{~K}$, thanks to the increase of laser power and telescope receiver size chosen for water vapor issues. Temperature radiosondes are better than $0.2 \mathrm{~K}$ and are given with an accurate geometric altitude as provided by the GPS receiver onboard. The differences between radiosondes and the lidar are mainly due to the gravity wave activity and the difference of the location due to the wind balloon drift compared to the lidar vertical sounding. Systematic comparisons will allow to us quantify the uncertainties, showing that no evident bias effects exist and that these profiles will ensure the lidar monitoring of the middle atmosphere temperature started in 1993 at the university at sea level.

\subsection{Wind Measurements}

The Rayleigh-Doppler wind lidar will provide the evolution of the two components of the horizontal wind with a temporal resolution ranging from $15 \mathrm{~min}$ in the UTLS to $2 \mathrm{~h}$ at the stratopause and an accuracy ranging from $1 \mathrm{~ms}^{-1}$ in the UTLS to 5 to $10 \mathrm{~ms}^{-1}$ in the stratopause. The wind lidar set-up at Maïdo is involved in the validation experiment of the space wind lidar ADMAeolus that will be launched in 2015. ADM-Aeolus is measuring the wind velocity projected on the lidar line of sight from the surface to $30 \mathrm{~km}$. One to two good colocations per week with the ground lidar are expected (distance $<100 \mathrm{~km}$ ) depending on the satellite orbit.

The Doppler wind radiometer WIRA (see Sec. 2.2) has been operated at the Maïdo observatory, La Réunion, since September 2013. A spectrometer problem (September/October 2013) and a tropical cyclone (TC) that had caused damage to a high frequency data cable (January/ February 2014) are responsible for major observation gaps. As an example, the daily average values of zonal wind measured by WIRA during this campaign are compared to European centre for medium-range weather forecasts (ECMWF) operational analyses in Fig. 5. The white lines delimit the trustable altitude range of the WIRA measurements (measurement response $>0.8$, altitude resolution $<16 \mathrm{~km}$, altitude accuracy $<4 \mathrm{~km}$, for details see Ref. 53). The overall agreement between WIRA and ECMWF is good, however, some differences become obvious, especially above the stratopause.

Simultaneous measurements between WIRA and the colocated double edge Doppler lidar in their common altitude range between 25 and $50 \mathrm{~km}$ will help to better characterize and understand such differences and allow better evaluation of the analyses of meteorological models. 


\section{Illustrations of Scientific Issues Addressed During the MALICCA}

In addition to the validations and cross comparisons, the campaign allows a good opportunity to provide a large documented observing data set well adapted to initiate investigations of targeted scientific objectives. While several studies will be the subject of specific analyses including numerical simulations, some illustrations of these analyses are provided.

\subsection{Dryness of the Troposphere due to the Injection of Stratospheric Air into the Troposphere}

It is now well established that stratospheric intrusions into the troposphere can occur in subtropical regions. The involved mechanisms are tropopause folds induced by the subtropical jet stream, which can be in interaction with tropical convective events or not, Rossby wave breaking or cut-off lows. ${ }^{61}$ The lidar instrumentation deployed at the Maïdo observatory allows the simultaneous production of high-resolution profiles of water vapor and ozone covering the whole free troposphere until the lower stratosphere.

During the MALICCA, enriched ozone (reaching more than 90 ppbv between 8 and $13 \mathrm{~km}$ on April 4, 2013) and dry $\left(10^{-2} \mathrm{~g} / \mathrm{kg}\right)$ air masses have been observed and distance themselves from the climatology. A synoptic analysis was performed until March 28 and shows that a Rossby wave breaking event coming from the west is detectable in the upper troposphere near the subtropical edge (Fig. 6). Potential vorticity maps from ERA-Interim ECMWF reanalysis show a complex situation characterized by series of several stratospheric thalwegs which move eastward, inducing several tropopause folds the following days until April 4. Simultaneously measuring the evolution of the two tracers, ozone and water vapor, and coupling with dynamical analyses based on mesoscale (Meso-NH), dispersion (FLEXPART) and reverse domain filling (LACYTRAJ) models allows us to recount the history of the air masses. These new observations will allow evaluating simulated mixing tropospheric ozone and water vapor and will be the subject of a specific study.

\subsection{Conditions for Cirrus Cloud Occurrences}

Cirrus cloud occurrences are a strong issue for climate as well as the understanding of the water transport distribution through the UTLS. Previous lidar analyses performed on the dataset obtained with the previous instruments have already shown that different classes of cirrus can be detected below the tropopause or around 8 to $10 \mathrm{~km}$. They are generated by either tropical

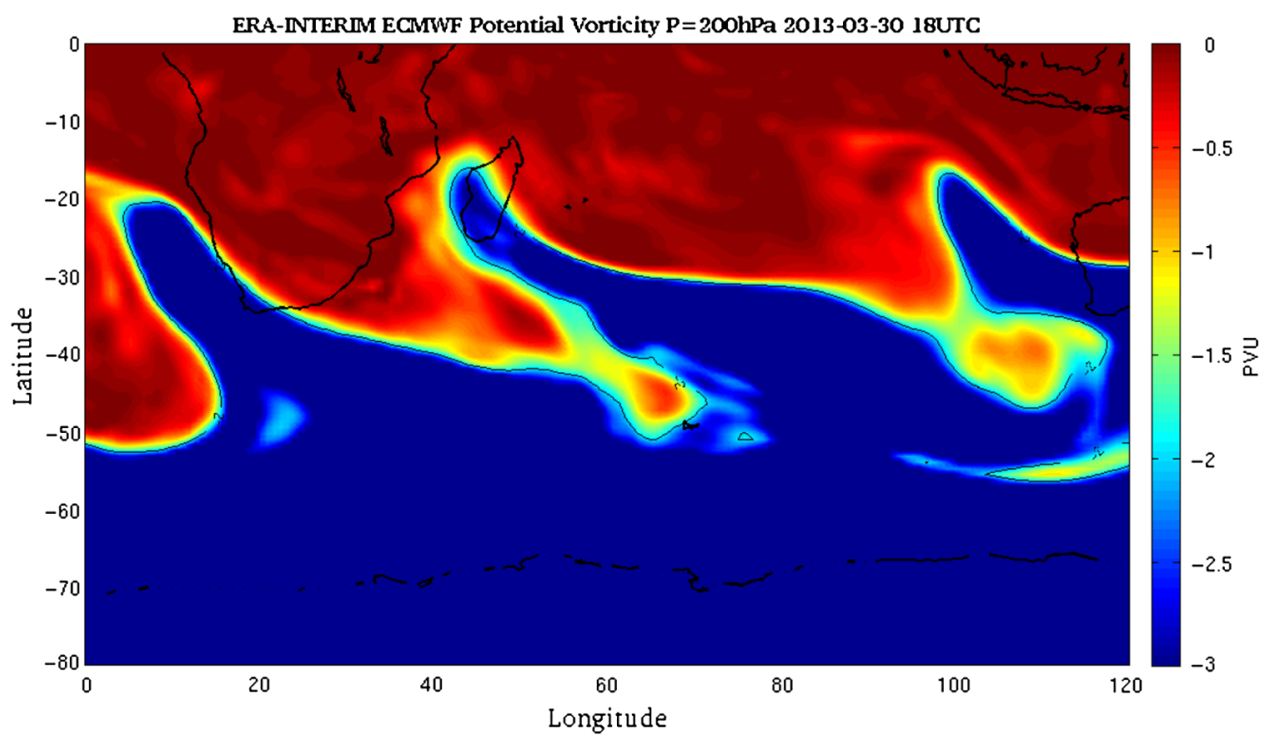

Fig. 6 Horizontal distribution of potential vorticity on March 30, 2013, 18:00 UT, on the $200 \mathrm{hPa}$ isobaric surface, from the ECMWF ERA-Interim reanalysis. 

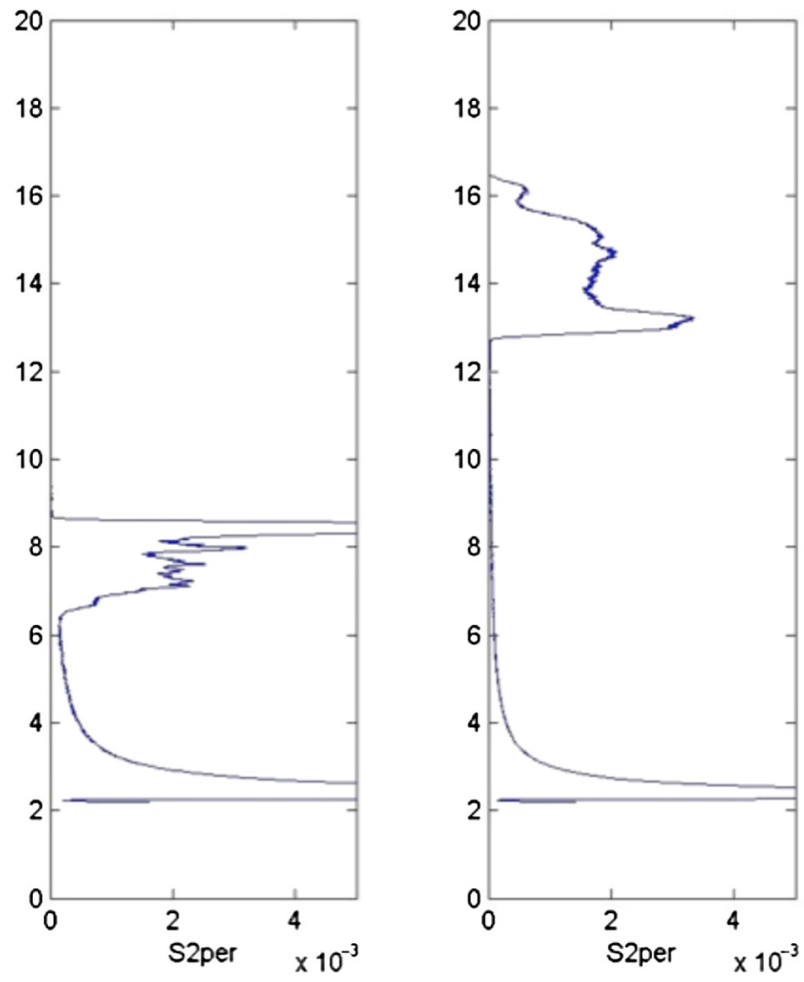

Fig. 7 Range-corrected lidar signals for two different types of clouds occurring, respectively (a) around 13 to $16 \mathrm{~km}$ on April 13, 2013, 16.40 UT (2-h integration time) and (b) around 6 to $8 \mathrm{~km}$ on April 5, 2013, 0.0 UT (30-min integration time) from the Leosphere lidar. Exponential decrease of the signal between 2 and $6 \mathrm{~km}$ is due to the molecular scattering while the enhancement corresponds to cirrus cloud altitudes.

storms and cyclones or by the subtropical jet stream. ${ }^{60}$ These clouds are associated with water vapor transported either vertically through convective towers or cyclonic structures or horizontally through the intercontinental transport linked with the jet. The net vertical transport of water vapor as well as the cirrus cloud lifetime depends on cirrus characteristics and the associated sedimentation processes that may be different according to the cloud type. Measurements performed at Maïdo will help to address this issue. During the MALICCA, different vertical distributions were observed. Figure 7 gives a good illustration of the different types of cirrus cloud observed.

Systematic measurements of the cloud occurrence with accurate water vapor measurements could be used to check the thermodynamical conditions of the tropical cirrus cloud formation and test if such conditions can differ depending on their origins. Different cirrus classes, dependent on their origin, can obey different thermodynamic conditions and they can be formed over long distances. Collocated measurements of cloud vertical distribution, temperature and water vapor provide a good opportunity to address this issue. In Fig. 8, a case study shows that the Lidar and the radiosonde yield large differences about the saturation conditions. While the radiosonde reveals humidity never larger than $50 \%$, which probably associated with an underestimation of the water vapor density, the lidar gives larger values closer to $100 \%$. However, those values sometimes correspond to cloud occurrences (15 to $16 \mathrm{~km})$, sometimes do not $(17 \mathrm{~km})$, and sometimes intermediated values are observed (13 to $15 \mathrm{~km})$ which may be due to clouds formed earlier and away from the measurement sites. The occurrence and conditions of ice super-saturation as well as the exact values are not yet fully determined. ${ }^{62}$ The data performed within the MALICCA will contribute to provide additional high quality measurements to improve our understanding of the tropical microphysics. Such a study for each cirrus cloud type (Fig. 8) will be performed according to the history of air masses. However, investigations on the water vapor data quality are required as it remains one of the most critical aspects for addressing such issues. 


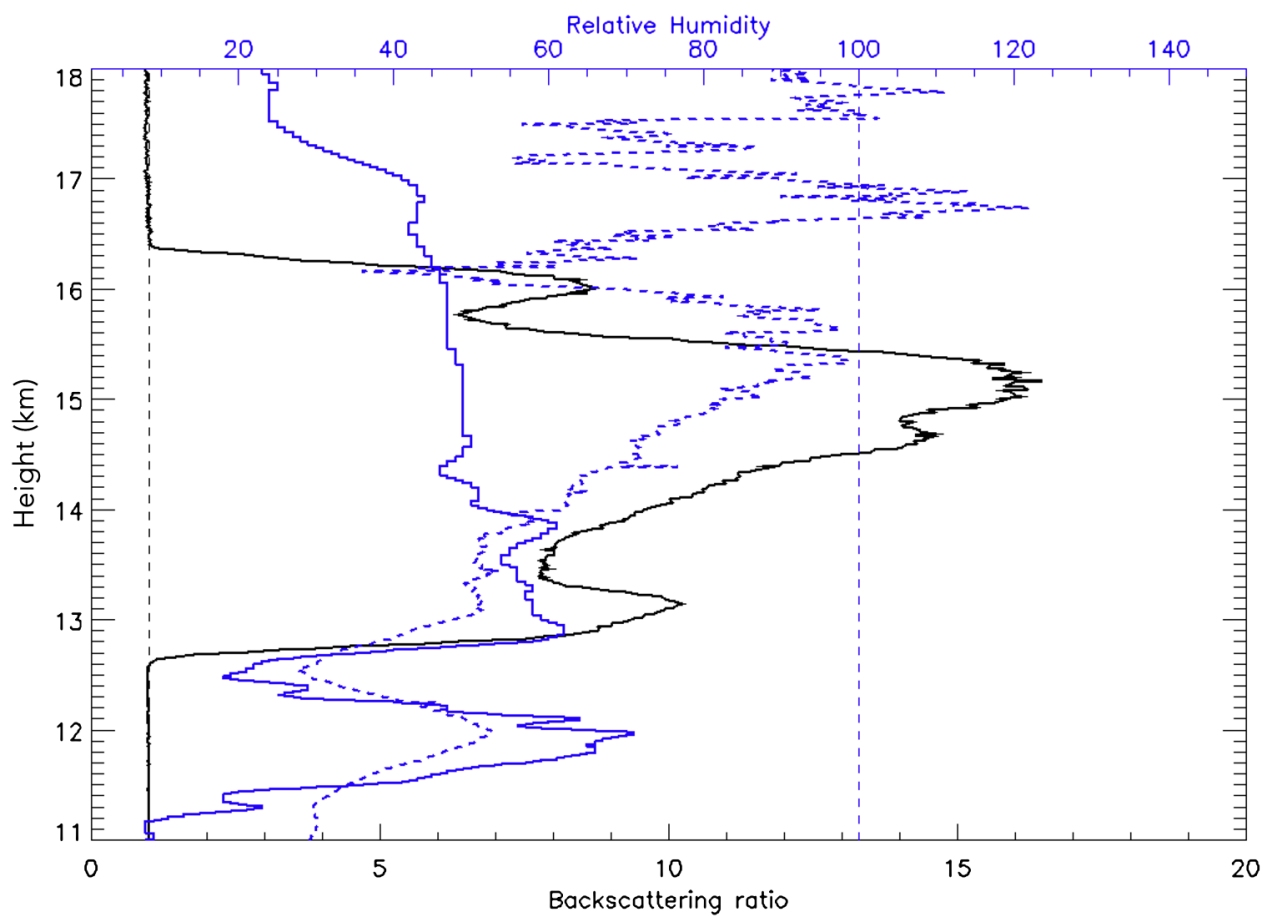

Fig. 8 Lidar backscattered profile showing the vertical distribution of clouds (dark line, bottom scale) and simultaneous relative humidity profiles derived with the RS92 radiosonde (blue strait line, top scale) and lidar (blue dashed line, top scale).

\subsection{Water Vapor Stratospheric Injection in the Vicinity of Cyclones}

During the second half of the campaign, TC Imelda occurred in the southwest Indian Ocean. The low-pressure system was located on April 6, 2013, northeast of Reunion Island. The system then strengthened by moving to the south to be closest to Reunion Island between April 14 and 15 as a TC (Fig. 9). The dynamic context over the Maïdo observatory was influenced by that system. Contrary to the first part of MALICCA-1 which was characterized by the dryness of the atmosphere due to stratospheric intrusions, strong values of humidity were visible in the UT/LS over the observatory especially between April 13 and 16 (Fig. 10). These differences are significant according to various uncertainties (Fig. 4). A preliminary study with a trajectographic model has been performed for the second part of the campaign and indicates that air masses around the tropopause over Reunion Island are the result of an important mixing of air coming from the

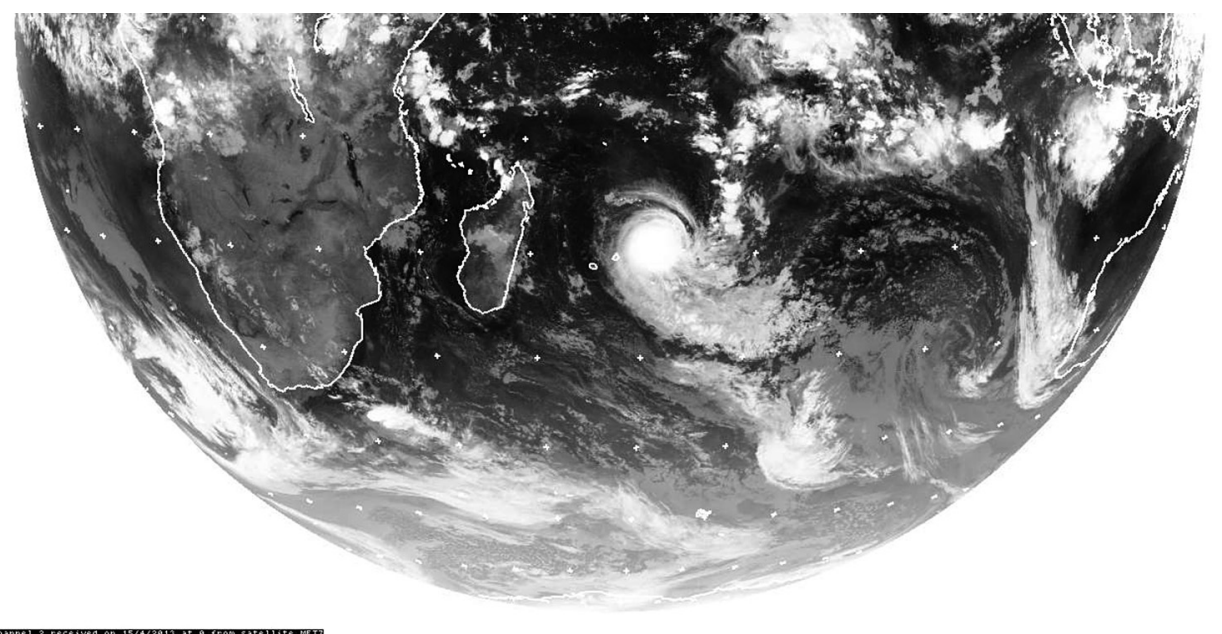

Fig. 9 Meteosat image on April 15, 2013, at 00:00 UTC in the infrared channel. 


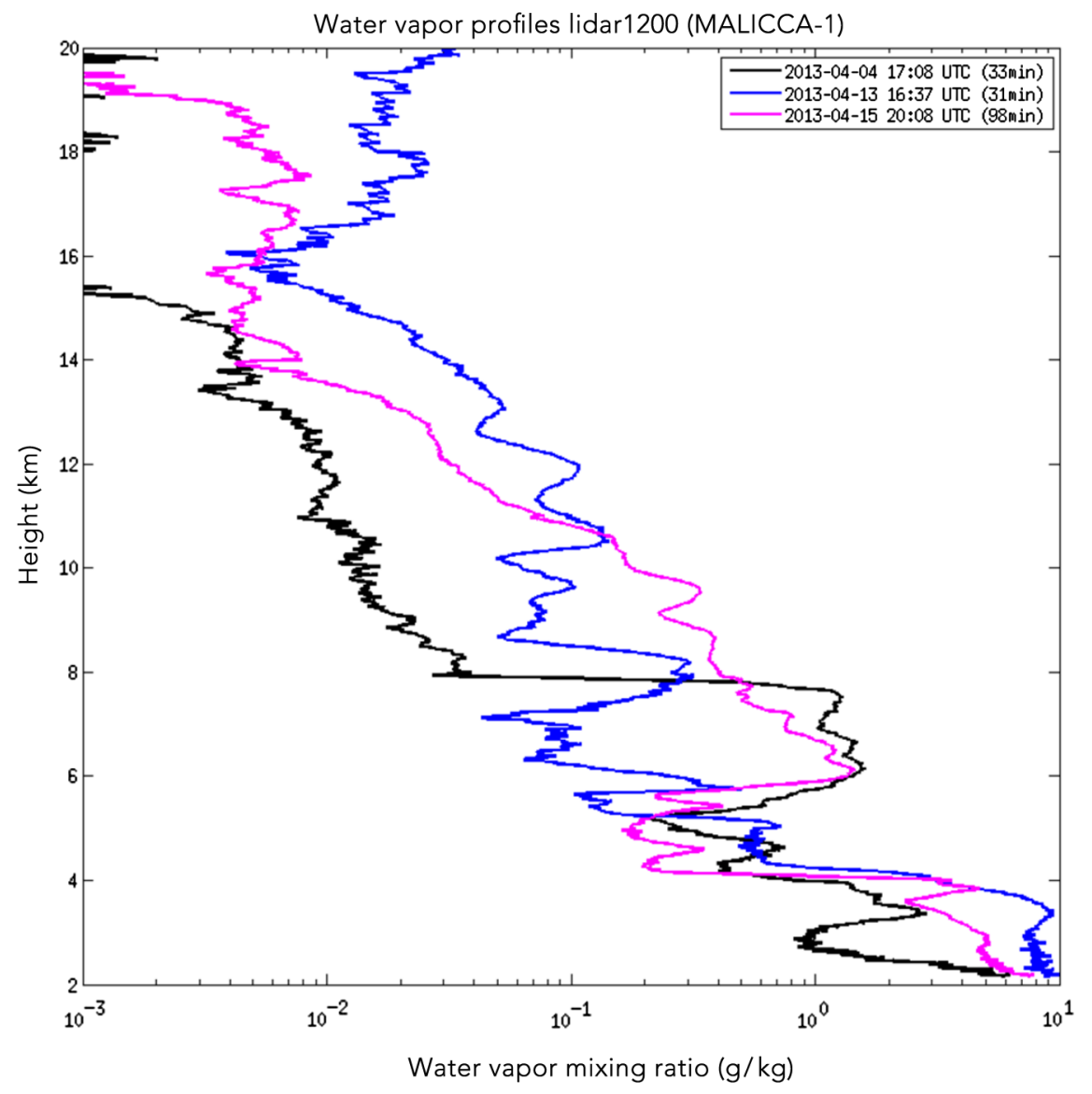

Fig. 10 Vertical profiles of water vapor mixing ratio obtained from Raman lidar of the Maïdo observatory, on April 4, 13, and 15, 2013. The last two days were associated with the presence of a cyclone crossing the Indian Ocean. Error bars appear on Fig. 4.

whole atmospheric column. Despite the fact that the lidar system needs clear sky to operate, we show its capability to measure significant amounts of water vapor reaching the lower stratosphere in the vicinity of strong convective events. Coupling the analysis of the original data set with satellite and model analyses, we will be able to document scientific questions such as the overshooting of water vapor in the tropical tropopause layer by deep convection or the role of cirrus clouds in the water vapor distributions in the UT-LS. Such a case study is a good opportunity to test whether the local structures and gradients observed with our instruments are realist.

\subsection{Gravity Waves and Mesospheric Inversions}

The combination of temperature measurements with the Rayleigh-Raman lidar and wind measurements with the Doppler lidar will allow studying stratospheric dynamical perturbations such as gravity waves, thermal tides, and Rossby and Kelvin planetary waves. From the common observations of horizontal wind and temperature perturbations induced by a gravity wave, it is possible to reconstruct all the characteristics of this wave, amplitude, period, vertical and horizontal wavelength, helping to identify its source. The dynamical information provided by the wind lidar will be also used to interpret observations of the transport of constituents like ozone and water vapor in the UTLS.

Figure 1 showing one comparison between radiosondes and the lidar reveals an inversion of the temperature gradient around $75 \mathrm{~km}$, showing a temperature anomaly of around $30 \mathrm{~K}$. Such an effect is frequently observed and can persist over several days. Mesospheric inversions explain most of the variability over the tropics and during summer at the mid-latitudes when planetary waves cannot propagate. ${ }^{63}$ The origin of such an effect was associated to different causes such as 
the gravity wave momentum deposition, ${ }^{64}$ interferences with planetary waves ${ }^{65}$ or tides. ${ }^{66}$ While such an effect is observed around the top of the lidar profiles, its amplitude and the gravity wave energy were not always accurately derived. The comparison of the mean vertical temperature gradient and the adiabatic (as described in Ref. 67) will allow us to better understand the physical processes involved. The improvement of the accuracy of temperature measurements will allow the derivation of a more accurate inversion amplitude, and the gravity waves' energy as well as tides and planetary waves. The relationship between these waves will allow a better understanding of the cause of such an effect and will also enable us to better quantify the occurrence of such effects.

\section{Conclusions}

A first calibration campaign called MALICCA was organized after the set up of the new high altitude observatory and the move of the instruments from the instrumental platform at the university campus at ground level to the new Maïdo facility. This first campaign was dedicated to meteorological/thermodynamic parameters (temperature, wind, water vapor, and cirrus clouds) while another campaign is already planned on the framework of the international network NDACC and will be dedicated to ozone and related parameters. Lidars, microwave instruments, balloon-borne sondes and spectrometers were involved. Nominal capabilities were achieved and an overall good agreement between instruments was obtained. This campaign also gave the opportunity to conduct dedicated studies about individual techniques and has allowed preliminary scientific investigations illustrating the potential of these measurements to address some scientific questions and the value of the Maïdo site. While a large data set was obtained, many specific studies have been conducted and will be published separately.

Instrument comparisons of the water vapor profiles show that the new Raman lidar calibrated with total column measurements (GPS) provides accurate measurements with an accuracy with Vaisala sondes of $10 \%$ up to $10 \mathrm{~km} .{ }^{55}$ Larger differences with Vaisala sondes are obtained (20\%) while Modem sondes show that a similar accuracy can be obtained when corrections similar to the one applied on the Vaïsala sondes are performed. Microwave measurements provide nominal profiles in the upper stratosphere to the mesosphere. Vertical adjustment between lidar and microwave profile will be addressed in a specific study while the overlap altitude range even if small is now.

The new lidar temperature instrument exhibits better capabilities (ranging up to more than $100 \mathrm{~km}$ ) than the previous one in operation at the university site since $1993,{ }^{68,32}$ and good comparisons with radiosondes have been obtained. New comparisons will be performed during the next NDACC campaign and will be the subject of a specific study and qualification with the NASA lidar, an investigation that will be done to ensure continuity with the last two decades of measurements performed with the previous lidar.

The wind measurement has been a new issue with the Maïdo observatory. It was the first time that such measurements have been performed at the same time with GPS-radiosondes, lidar, and microwaves radiometers. While very promising measurements were obtained with both techniques, with sensitivities on the order of $1 \mathrm{~ms}^{-1}$, a specific validation study is in preparation. Direct comparisons are difficult to achieve when all the measurements exhibit slightly different altitude ranges and very different vertical resolutions.

The purpose of these measurements consists primarily of monitoring the vertical profile of the thermodynamic parameters along with the composition (NDACC issues), but also to address, during the next decades, some specific scientific questions. The first one consists of the tropospheric-stratospheric exchanges in both directions. Two illustrations were given here that occurred during the campaign with a case of exchange related to Rossby waves breaking and one related to a cyclone episode in the Indian Ocean.

A better knowledge of the water cycle in the vicinity of the tropopause and its transport involves the crystal phase, known as cirrus clouds. Different classes due to convection or transport were already observed with lidar ${ }^{60}$ indicating different formation processes. However, independent of their origin, the study of their occurrence in connection with the water vapor content and their potential sur-saturation effects require an accurate knowledge of water vapor density as illustrated in Fig. 9, and both lidar and sonde accuracies are again a key 
issue to address in the next years with the Maïdo facility. A better understanding of the tropical dynamics will be possible with both temperature and wind measurements while the local effect of gravity waves is crucial for better understanding the evolution of the mesosphere. Temperature mesospheric inversions that are proposed to be due to the breaking of gravity waves are frequently observed above La Réunion island as illustrated in Fig. 1, and the improved temperature accuracy and altitude range with the new lidar will allow better study the mesosphere evolution and its impact on water vapor content.

\section{Acknowledgments}

Fundings to these campaigns were supported by CNRS/INSU, CNES and Reunion Island University. Microtops sunphotometer calibrations and data validation were supported by NASA in the framework of the Maritime AERONET NETWORK. Meteo France and INSU provided a logistical and technical support for VAISALA radiosoundings. European Committee (FEDER), Reunion Island Council, CNRS/INSU, Reunion Island University and the French Ministry of Research supported Maïdo Facility either for the building, for the instrument developments and for operation. Meteosat image credited to NERC Satellite Receiving Station, Dundee University, Scotland-http://www.sat.dundee.ac.uk/. We acknowledge the ECMWF center for providing global analyses and the UCAR CDAAC data center (http://cdaac-www.cosmic.ucar.edu/ cdaac/) for providing COSMIC data. The microwave instruments MIAWARA-C and WIRA are funded by the Swiss National Science foundation under contract 200020-146388. Data were publicly available through the international NDACC database (http:// www.ndsc.ncep.noaa.gov/data/), the French thematic chemistry center ETHER (http:// www.pole-ether.fr/), and the local database 5 of OPAR (https://opar.univ-reunion.fr/) where graphics and numerical tools are available.

\section{References}

1. M. J. Kurylo and S. Solomon, "Network for the detection of stratospheric change," NASA Report, Code EEU (1990).

2. M. Schneider et al., "Continuous quality assessment of atmospheric water vapour measurement techniques: FTIR, Cimel, MFRSR, GPS, and Vaisala RS92," Atmos. Meas. Tech. 3, 323-338 (2010).

3. http://www.icos-infrastructure.eu/.

4. K. Tørseth et al., "Introduction to the European Monitoring and Evaluation Programme (EMEP) and observed atmospheric composition change during 1972-2009," Atmos. Chem. Phys. 12, 5447-5481 (2012).

5. J. Bösenberg et al., "A European aerosol research lidar network to establish an aerosol climatology," MPI-Report 317, (Max-Planck Inst. für Meteorology, Hamburg, Germany 2003).

6. D. J. Gaffen, "Temporal inhomogeneities in radiosonde temperature records," J. Geophys. Res. 99, 3667-3676 (1994).

7. C. G. Wade, "An evaluation of problems affecting the measurement of low relative humidity on the United States radiosonde," J. Atmos. Ocean. Technol. 11, 687-700 (1994).

8. J. R. Lanzante, "Resistant, robust and nonparametric techniques for the analysis of climate data: theory and examples, including applications to historical radiosonde station data," Int. J. Climatol. 16, 1197-1226 (1996).

9. L. Haimberger, C. Tavolato, and S. Sperka, "Toward elimination of the warm bias in historic radiosonde temperature records-some new results from a comprehensive intercomparison of upper-air data," J. Clim. 21, 4587-4606 (2008).

10. W. J. Randel and F. Wu, "Biases in stratospheric and tropospheric temperature trends derived from historical radiosonde data," J. Clim. 19, 2094-2104 (2006).

11. K. E. Trenberth, T. R. Karl, and T. W. Spence, "The need for a systems approach to climate observations," Bull. Am. Meteor. Soc. 83, 1558-1559 (2002). 
12. D. W. J. Thompson et al., "The mystery of recent stratospheric temperature trends," Nature 491, 692-697 (2012).

13. P. M. Forster and K. P. Shine, "Stratospheric water vapour changes as a possible contributor to observed stratospheric cooling," Geophys. Res. Lett. 26, 3309-3312 (1999).

14. I. M. Held and B. J. Soden, "Water vapor feedback and global warming," Annu. Rev. Energy Environ. 25, 441-475 (2000).

15. N. Montoux et al., "Evaluation of balloon and satellite water vapour measurements in the southern tropical and subtropical UTLS during the HIBISCUS campaign," Atmos. Chem. Phys. 9, 5299-5319 (2009).

16. K. N. Liou, "Influence of cirrus clouds on weather and climate processes: a global perspective," Mon. Weather Rev. 114, 1167-1199 (1986).

17. B. N. Holben et al., "A federated instrument network and data archive for aerosol characterization," Remote Sens. Environ. 66(1), 1-16 (1998).

18. D. N. Kafle and R. L. Coulter, "Micropulse lidar-derived aerosol optical depth climatology at ARM sites worldwide," J. Geophys. Res. Atmos. 118, 7293-7308 (2013).

19. A. Behrendt et al., "Intercomparison of water vapor data measured with lidar during IHOP 2002, Part 1: Airborne to ground-based lidar systems and comparisons with chilled-mirror hygrometer 1005 radiosondes," J. Atmos. Oceanic Technol. 24, 3-21 (2007).

20. T. Leblanc et al., "Measurements of Humidity in the Atmosphere and Validation Experiments (MOHAVE)-2009: overview of campaign operations and results," Atmos. Meas. Tech. 4, 2579-2605 (2011).

21. R. Bhawar et al., "The water vapour intercomparison effort in the framework of the convective and orographically-induced precipitation study: air-borne-to-ground-based and airborne-to-airborne lidar systems. COPS Special Issue of the Q," J. R. Meteorol. Soc. 137(S1), 325-348 (2011).

22. G. E. Nedoluha et al., "Validation of long-term measurements of water vapor from the midstratosphere to the mesosphere at two network for the detection of atmospheric composition change sites," J. Geophys. Res. 118, 934-942 (2013).

23. O. Bock et al., "Accuracy assessment of water vapour measurements from in situ and remote sensing techniques during the DEMEVAP 2011 campaign at OHP," Atmos. Meas. Tech. 6, 2777-2802 (2013).

24. J. L. Baray et al., "An instrumented station for the survey of ozone and climate change in the southern tropics: scientific motivation, technical description and future plans," J. Environ. Monit. 8, 1020-1028 (2006).

25. P. S. Keckhut et al., "Review of ozone and temperature lidar validations performed within the framework of the network for the detection of stratospheric change," J. Environ. Monit. 6, 721-733 (2004).

26. A. Haefele et al., "Validation of ground-based microwave radiometers at $22 \mathrm{GHz}$ for stratospheric and mesospheric water vapor," J. Geophys. Res. 114(D23305) (2009).

27. G. J. Herman et al., "Assessment of the performance of ECC-ozonesondes under quasiflight conditions in the environmental simulation chamber: insights from the Juelich Ozone Sonde Intercomparison Experiment (JOSIE)," J. Geophys. Res. 112(D19) (2007).

28. J.-L. Baray et al., "Maïdo observatory: a new high-altitude station facility at Reunion Island $\left(21^{\circ} \mathrm{S}, 55^{\circ} \mathrm{E}\right)$ for long-term atmospheric remote sensing and in situ measurements," Atmos. Meas. Tech. 6, 2865-2877 (2013).

29. D. Lesouëf et al., "Numerical simulations of local circulations and pollution transport over Reunion Island," Ann. Geophys. 29, 53-69 (2011).

30. A. Hauchecorne et al., "Lidar monitoring of the temperature in the middle and lower atmosphere," Appl. Phys. B 55(1), 29-34 (1992).

31. P. Keckhut, A. Hauchecorne, and M. L. Chanin, "A critical review on the database acquired for the long term surveillance of the middle atmosphere by French Rayleigh lidars," J. Atmos. Oceanic Technol. 10, 850-867 (1993).

32. P. Keckhut et al., "An evaluation of uncertainties in monitoring middle atmosphere temperatures with the lidar network in support of space observation," J. Atmos. Sol. Terr. Phys. 73(5-6), 627-642 (2011). 
33. P. Keckhut et al., "A review of ozone and temperature lidar validations performed within the framework of the network for the detection of stratospheric change," J. Environ. Monit. 6, 721-733 (2004).

34. F. J. Immler et al., "Reference quality upper-air measurements: guidance for developing GRUAN data products," Atmos. Meas. Tech. 3, 1217-1231 (2010).

35. C. Hoareau et al., "Methodology for water monitoring in upper troposphere with Raman lidar at Observatory of Haute-Provence," J. Atmos. Oceanic Technol. 26(10), 2149-2160 (2009).

36. V. Duflot et al., "Marine and biomass burning aerosols in the southern Indian Ocean: Retrieval of aerosol optical properties from shipborne lidar and Sun photometer measurements," J. Geophys. Res. 116, D18208 (2011).

37. G. Vaughan et al., "Water vapour and ozone profiles in the midlatitude upper troposphere," Atmos. Chem. Phys. 5, 963-971 (2005).

38. M. Bevis et al., "GPS meteorology: remote sensing of the atmospheric water vapor using the global positioning system," J. Geophys. Res. 97, 15787-15801 (1992).

39. M. Schneider et al., "Remote sensing of water vapour profiles in the framework of the Total Carbon Column Observing Network (TCCON)," Atmos. Meas. Tech. 3, 1785-1795 (2010).

40. C. F. Champollion et al., "GPS water vapour tomography: preliminary results from the ESCOMPTE field experiment," Atmos. Res. 74(1-4), 253-274 (2005).

41. A. Smirnov et al., "Maritime aerosol network as a component of AERONET—first results and comparison with global aerosol models and satellite retrievals," Atmos. Meas. Tech. 4, 583-597 (2011).

42. A. Smirnov et al., "Effect of wind speed on aerosol optical depth over remote oceans, based on data from the Maritime Aerosol Network," Atmos. Meas. Tech. 5, 377-388 (2012).

43. A. Smirnov et al., "Maritime Aerosol Network as a component of Aerosol Robotic Network," J. Geophys. Res. 114, D06204 (2009).

44. N. Kämpfer, Ed., Monitoring Atmospheric Water Vapour-Ground-based Remote Sensing and in situ Methods, ISSI Scientific Report Series 10, Springer (2013).

45. N. Kämpfer et al., "Microwave radiometry, Chapter 5 in Monitoring Atmospheric Water Vapour, N. Kämpfer, Ed., ISSI Scientific Report Series 10, Springer (2013).

46. E. Motte et al., "A $22 \mathrm{GHz}$ Mobile Microwave Radiometer (MobRa) for the study of stratospheric water vapor," IEEE Tran. Geosci. Remote Sens. 46, 3104-3114 (2008).

47. J. Urban et al., "A versatile forward- and inversion model for the millimetre and submillimeter wavelength range," J. Quant. Spectrosc. Radiat. Transfer 83(3-4), 529-554 (2004).

48. C. Straub et al., MIAWARA-C, a new ground based water vapor radiometer for measurement campaigns," Atmos. Meas. Tech. 3, 1271-1285 (2010).

49. B. Tschanz et al., "Validation of middle-atmospheric campaign-based water vapour measured by the ground-based microwave radiometer MIAWARA-C," Atmos. Meas. Tech. 6 , 1725-1745 (2013).

50. M. L. Chanin et al., "A Doppler lidar for measuring winds in the middle atmosphere," Geophys. Res. Lett. 16(11), 1273 (1989).

51. S. C. A. Garnier et al., "Rayleigh-Mie Doppler wind lidar for atmospheric measurement. I. Instrumental set-up, validation and first climatological results," Appl. Opt. 38, 2410-2421 (1999).

52. A. Hertzog, C. Souprayen, and A. Hauchecorne, "Measurements of gravity wave activity in the lower stratosphere by Doppler lidar," J. Geophys. Res. 106, 7879-7890 (2001).

53. R. Rüfenacht et al., "Middle-atmospheric zonal and meridional wind profiles from polar, tropical and mid latitudes with the ground-based microwave Doppler wind radiometer WIRA," Atmos. Meas. Tech. 7, 4491-4505 (2014).

54. L. M. Miloshevich et al., "Absolute accuracy of water vapor measurements from six operational radiosondes types launched during AWEX-G and implications for AIRS validation," J. Geophys. Res. 111, D09S10 (2006).

55. D. Dionisi et al., "Water vapor observations up to the lower stratosphere using the Raman lidar during the Maïdo Lidar Calibration Campaign," Atmos. Meas. Tech. 8, 1425-1445 (2015). 
56. A. Gettelman et al., "Validation of Aqua satellite data in the upper troposphere and lower stratosphere with in situ aircraft instruments," Geophys. Res. Lett. 31, L22107 (2004).

57. D. E. Hagan et al., "Validating AIRS upper atmosphere water vapor retrievals using aircraft and balloon in situ measurements," Geophys. Res. Lett. 31, L21103 (2004).

58. D. N. Whiteman et al., "Analysis of Raman lidar and radiosonde measurements from the AWEX-G field campaign and its relation to Aqua validation," J. Geophys. Res. 111, D09S09 (2006).

59. J. E. Barnes et al., "NASA/Aura/Microwave Limb Sounder water vapor validation at Mauna Loa Observatory by Raman lidar," J. Geophys. Res. 113, D15S03 (2008).

60. C. Hoareau et al., "A Raman lidar at La Reunion $\left(20.8^{\circ} \mathrm{S}, 55.5^{\circ} \mathrm{E}\right)$ for monitoring water vapour and cirrus distributions in the subtropical upper troposphere: preliminary analyses and description of a future system," Atmos. Meas. Tech. 5, 1333-1348 (2012).

61. J. L. Baray et al., "Subtropical tropopause break as a possible stratospheric source of ozone in the tropical troposphere," J. Atmos. Sol. Terr. Phys. 60(1), 27-36 (1998).

62. M. Krämer et al., "Ice supersaturations and cirrus cloud crystal numbers," Atmos. Chem. Phys. 9, 3505-3522 (2009).

63. P. Keckhut et al., "Modes of variability of the vertical temperature profile of the middle atmosphere at mid-latitude: similarities with solar forcing," J. Atmos. Sol. Terr. Phys. 75-76(92-97) (2012).

64. A. Hauchecorne and A. Maillard, "A 2-D dynamical model of mesospheric temperature inversions in winter," Geophys. Res. Lett. 17, 2197-2200 (1990).

65. F. Sassi et al., "On temperature inversions and the mesospheric surf zone," J. Geophys. Res. 107(D19), 4380 (2002).

66. J. W. Meriwether et al., "Observed coupling of the mesospheric inversion layer to the thermal tidal structure," Geophys. Res. Lett. 25, 1479-1482 (1998).

67. R. J. Sica et al., "Model-measurement comparison of mesospheric temperature inversions, and a simple theory for their occurrence," Geophys. Res. Lett. 34, L23806 (2007).

68. D. Faduilhe et al., "Stratospheric temperature monitoring using a vibrational Raman lidar. Part 1: aerosols and ozone interferences," J. Environ. Monit. 7, 357-364 (2005).

Philippe Keckhut defended his $\mathrm{PhD}$ in 1991 at Paris 6 University. He is now professor at University of Versailles Saint-Quentin and the director of the LATMOS laboratory. He has 25 years of research experience in the field of atmospheric instrumentation and climatology, published 114 peer-reviewed articles (H-index: 29), and was awarded the Norbert-Gerbier Mumn prizes from the World Meteorological Organization. He is the PI of the H2O Raman lidar operating at La Réunion.

Yann Courcoux is a research engineer at CNRS and graduated from ENSTA Bretagne. He has 12 years of experience in lidar development and was project manager of the Maido Observatory design. He took part in the design of the lidars and organized the campaign and the measurements.

Jean-Luc Baray defended his $\mathrm{PhD}$ in 1999 at Paris 6 University. He is now working at University Blaise Pascal-Clermont Ferrand, but he was at Reunion University in charge of Lidar instruments at OPAR when the MALICCA campaign was conducted. His field of research is tropospheric dynamic, water vapor and ozone concentrations in the atmosphere, stratospheretroposphere exchanges, and remote sensing measurements.

Jacques Porteneuve is a CNRS engineer graduated from Ecole supérieure d'optique. He has developed many optical devices for atmospheric and space studies. He has designed many lidars in operation all around the planet, including those in operation at La Réunion. He was awarded in 2004 the CNRS Cristal for innovation.

Hélène Vérèmes is a $\mathrm{PhD}$ student (LACy/OSU-Réunion) in atmospheric physics. Her research project is focused on the water vapor in the troposphere and in the lower stratosphere in the (sub) tropical area and some atmospheric processes associated. She works on high resolution water 
vapor profiles from the H2O Raman lidar operating at the Maïdo observatory (Reunion Island) and from various local radio soundings.

Alain Hauchecorne defended his $\mathrm{PhD}$ in 1983 at Paris 6 University. He is senior scientist at CNRS-LATMOS. He has 35 years of experience in development of lidar technology for the study of Earth atmospheric dynamics and physics. He published 200 peer-reviewed articles (h-index 39), and he is a member of the French Academy of Air and Space.

Davide Dionisi's distinctive feature of the research activity is the employment of the lidar technique as a survey instrument of the atmosphere. He defended his $\mathrm{PhD}$ at La Sapienza University of Rome in 2011. In April 2012, he won a FP7 grant as a junior researcher at LATMOS in France. He participated to the validation of the H2O Raman lidar installed at the observatory of Maïdo (La Réunion). Since April 2014, he has been a temporary researcher at ISAC in Rome.

Francoise Posny defended her PhD in 1979 at the Pierre et Marie Curie University (Paris 6). She is currently professor assistant at the University ot La Reunion Island at the Physics Department and at the Laboratoire de l'Atmosphère et des Cyclones (LACy). She is the PI of the radiosounding profile measurements (ozone, temperature, relative humidity, GPS and wind) for the NDACC and SHADOZ networks.

Jean-Pierre Cammas defended his $\mathrm{PhD}$ in 1988 at University Blaise Pascal, France. He is now research director at CNRS and head of the Observatoire des Sciences de l'Univers at La Réunion. He has 28 years of research experience in the field of atmospheric dynamics, stratosphere-troposphere exchanges, and long-range transport processes. He published about 90 peer-reviewed articles (H-index: 21). He has participated and coordinated several European projects in the FP7 and H2020 frameworks.

Guillaume Payen is a research engineer at the university of Reunion Island and graduated from ENSSAT engineer school. He has 5 years of experience in lidar. He has been the technical coordinator of the Maïdo observatory since 2013 and works on lidars algortihms.

Franck Gabarrot is a CNRS engineer (OSU-Réunion). He has 12 years of experience in data management and software development for atmospheric sciences. He has designed the Maido Observatory computer system and network access. He works on software developments for lidar retrieval and observatory data management. He is in charge of OPAR information system and he assists teams for instrument installation and operation.

Stephanie Evan received her PhD in 2011 from the University of Colorado. In 2012, she joined the NOAA laboratory, where she has worked extensively on issues pertaining to the tropical tropopause layer and stratospheric dynamics using models, satellite and airborne data. Since December 2013, she has worked at LACy as a CNRS researcher. Her research focuses on the dynamics and chemical composition of the tropical UTLS and involves satellite data and lidar measurements.

Sergey Khaykin, PhD since 2005, is a researcher at LATMOS laboratory of CNRS and University of Versailles Saint-Quentin. He has 12 years of research experience in atmospheric instrumentation as well as atmospheric composition and dynamics and published 29 peerreviewed papers (h-index: 9). He is a co-PI of the Doppler wind lidar at La Réunion.

Rolf Rüfenacht recieved his MS degree in physics from the University of Bern, Switzerland, in 2010. He is currently working towards the $\mathrm{PhD}$ degree in atmospheric radiometry at the Institute of Applied Physics, University of Bern. His research interests are in the areas of microwave remote sensing of the middle atmosphere. His current activities are focussed on the development of ground-based Doppler radiometry for middle-atmospheric wind measurements and on atmospheric dynamics studies based on measurements from the wind radiometer WIRA.

Brigitte Tschanz is currently working towards the $\mathrm{PhD}$ degree in atmospheric radiometry at the Institute of Applied Physics, University of Bern. Her research project is focussed on middleatmospheric water vapour radiometry and she is mainly working with MIAWARA-C. 
Niklaus Kämpfer got a PhD in 1983 from the University of Bern for the investigation of solar flares. Thereafter he changed his field of interest and pursued research in microwave remote sensing of the atmosphere. Since 1994 he has been a professor for applied physics and head of the microwave physics department at the University of Bern. His team has been involved in the development of outstanding microwave receivers, such as the first mobile water vapor radiometer or the first fully automatic microwave wind profiler.

Philippe Ricaud defended his PhD in 1991 at Bordeaux Observatory. He is now senior scientist at Meteo-France (Toulouse, France). He has 25 years of research experience in the field of atmospheric instrumentation and climatology and published about 80 peer-reviewed articles (H-index: 21). He has installed the DODO microwave radiometer at La Réunion.

Abdel Abchiche, graduated from ENSEEC Caen in Normandy and is currently a research engineer at the Technical Division of INSU/CNRS. First designer of electronic systems of onboard aircraft lidars for twenty years, he is actuellemet project manager of instruments used in the 4 research areas of INSU. He was in charge of the control command radiometer DODO and its installation at the observatory of Maido during MALICCA campaign.

Jimmy Leclair de Bellevue defended his $\mathrm{PhD}$ in 2006 at the Université de la Réunion. He is now assistant professor at the Laboratoire de l'Atmosphère et des Cyclones (LACy), and investigator of GNSS observations for atmospheric water vapor retrieval at the Observatoire de Physique de l'Atmosphère de la Réunion (OPAR).

Valentin Duflot defended his PhD in 2011 at the Université de la Réunion. He is now PhysicienAdjoint SCOA at the Laboratoire de l'Atmosphère et des Cyclones (LACy), and the scientific coordinator of the Observatoire de Physique de l'Atmosphère de la Réunion (OPAR). He is the Co-I of the H2O Raman lidar and PI of the tropospheric ozone lidar, mobile aerosols lidar, and handheld photometers operating at la Réunion. 